No.2012-09

\title{
BUSINESS CYCLE IMPLICATIONS OF INTERNAL CONSUMPTION HABIT FOR NEW KEYNESIAN MODELS
}

\author{
Takashi $\mathrm{Kano}^{\dagger}$ \\ Department of Economics \\ Hitotsubashi University \\ 2-1 Naka \\ Kunitachi City \\ Tokyo 186-8601, JAPAN \\ e-mail: tkano@econ.hit-u.ac.jp
}

\author{
James M. Nason \\ Research Department \\ Federal Reserve Bank of Philadelphia \\ Ten Independence Mall \\ Philadelphia, PA \\ U.S.A. $19106-1574$ \\ e-mail: jim.nason@phil.frb.org
}

Current Draft: November 29, 2012

\begin{abstract}
We study the implications of internal consumption habit for new Keynesian dynamic stochastic general equilibrium (NKDSGE) models. Bayesian Monte Carlo methods are employed to evaluate NKDSGE model fit. Simulation experiments show that internal consumption habit often improves the ability of NKDSGE models to match the spectra of output and consumption growth. Nonetheless, the fit of NKDSGE models with internal consumption habit is susceptible to the sources of nominal rigidity, to spectra identified by permanent productivity shocks, to the choice of monetary policy rule, and to the frequencies used for evaluation. These vulnerabilities indicate that the specification of NKDSGE models is fragile.
\end{abstract}

Key Words: Consumption Habit; New Keynesian; Propagation; Monetary Transmission; Posterior Predictive Analysis; Bayesian Monte Carlo.

JEL Classification Number: E10, E20, E32.

\footnotetext{
${ }^{\dagger}$ We thank the editor (Pok-sang Lam), Evan Anderson, Heather Anderson, Jeannine Bailliu, Hafedh Bouakez, Toni Braun, Fabio Canova, Youngsung Chang, Richard Dennis, Mick Devereux, Mike Dotsey, Bill Dupor, Jon Faust, Martin Fukač, John Geweke, Pablo Guerrón-Quintana, Tasos Karantounias, Keith Kuester, Thomas Lubik, Christian Matthes, Ricardo Nunes, Adrian Pagan, B. Ravikumar, Pedro Silos, Larry Schembri, Tan Wang, Tao Zha, and seminar and session participants at the Bank of Japan, the Bank of Canada, the 2004 Far Eastern Meetings of the Econometric Society, the 10th International Conference on Computing in Economics and Finance (July 2004), the 2007 Summer Meetings of the Econometric Society, HEC Montréal, Hitotsubashi University, the University of Tokyo, Kobe University, the Federal Reserve Bank of Atlanta's macro lunch workshop, Yonsei University, the Workshop on Methods and Applications for DSGE Models at the Federal Reserve Bank of Cleveland (October 2008), the 2008 Reserve Bank of Australia Research Workshop, "Monetary Policy in Open Economies," the Federal Reserve Bank of Philadelphia, Northern Illinois University, the System Macro Committee Meeting at the Federal Reserve Bank of San Francisco (May 2009), Hong Kong University of Science and Technology, Keio University, Tohoku University, Osaka University, and Johns Hopkins University for useful discussions. An early version of this paper circulated as "Business Cycle Implications of Internal Habit Formation." The first author wishes to thank the Ministry of Education, Culture, Sports, Science, and Technology of the government of Japan for support from a grant-in-aid for scientific research (number 20730205). The views in this paper represent those of the authors and are not those of the Federal Reserve Bank of Philadelphia or the Federal Reserve System.
} 


\section{INTRODUCTION}

This paper evaluates the impact of internal consumption habit on the empirical fit of new Keynesian dynamic stochastic general equilibrium (NKDSGE) models. Consumption habit is often superinduced in DSGE models to improve fit, but the role consumption habit has in a NKDSGE model is not settled. For example, Del Negro, Schorfheide, Smets, and Wouters (2007) find that consumption habit contributes to a NKDSGE model matching the hump-shaped response of output to a Taylor rule shock, but Christiano, Eichenbaum, and Evans (2005) do not; instead they use a money growth shock.

This is not the case for real business cycle (RBC) models. Consumption habit is known to be successful at closing the distance between RBC models and aggregate quantity and asset price moments since the work of Boldrin, Christiano, and Fisher (2001). ${ }^{1}$ An explanation for this success, suggested by Eichenbaum and Hansen (1990) and Heaton (1995), is that consumption habit is a real friction that imposes costs when a household substitutes utility intertemporally.

We present an experiment using a log linearized Euler equation that studies the effects the utility costs of internal consumption habit have in inducing intertemporal complementarity in consumption growth from date $t$ to date $t+j, j>1$, instead of intertemporal substitution in the level of consumption between dates $t$ and $t+1$. The experiment shows that as internal consumption habit increases in utility, the household reacts to a positive real interest rate shock by pushing the peak response in its consumption growth from date $t+1$ to date $t+j$. The experiment also documents that frequency by frequency the variance of consumption growth falls steadily across the entire spectrum holding internal consumption habit fixed. As internal consumption habit increases, the spectral density $(S D)$ of consumption growth exhibits less and less amplitude frequency by frequency. ${ }^{2}$

Beyond this experiment, the implications of internal consumption habit for NKDSGE models are studied using several population moments. Our analysis relies on population moments because, as Geweke (2010) argues, confronting the predictive density of a DSGE model with a sufficiently large vector of sample moments almost surely negates it. Geweke (2010) proposes the minimal econometric interpretation (MEI) of DSGE models to address this problem. Under the MEI, priors on the DSGE model yield a distribution for population moments, but neither for the actual data (i.e., the model's likelihood)

1. Consumption habit is first grafted into a growth model by Ryder and Heal (1973). Nason (1988), Sundaresan (1989), and Constantinides (1990) are early attempts at solving risk-free rate and equity premium puzzles with consumption habit. Pollak (1976) shows that long-run utility with linear habit describes long-run behavior rather than long-run preferences. Rozen (2010) gives an axiomatic treatment of linear intrinsic habit. An excellent survey of consumption habit in macro and finance is Schmitt-Grohé and Uribe (2007); also see Nason (1997).

2. Otrok, Ravikumar, and Whiteman (2002) make a similar point using spectral utility analysis. 
nor for sample moments. We employ the MEI to evaluate 12 NKDSGE models on posterior and prior population moments by adapting Bayesian Monte Carlo methods developed by DeJong, Ingram, and Whiteman (1996), Geweke (1999), and McCausland (2004). ${ }^{3}$

This paper evaluates the fit of NKDSGE models with and without internal consumption habit on permanent and transitory SDs of output and consumption growth. Our choice of these moments is guided by earlier studies of the U.S. business cycle. Among others, Galí (1991) finds that the $S D$ of consumption growth is not flat, which violates the permanent income hypothesis (PIH). Cogley and Nason (1995b) observe that RBC models cannot reproduce the $S D$ of output growth because it peaks in the business cycle frequencies. They show, along with Nason and Cogley (1994), that DSGE models fail to duplicate output's response to permanent and transitory shocks. Thus, we explore NKDSGE model fit on moments known to have power to judge competing theories of the U.S. business cycle.

The identification of permanent and transitory SDs relies on output and consumption being orthogonal to transitory nominal shocks in the long run. This long-run monetary neutrality (LRMN) restriction is used to identify posterior population $S D$ s estimated from structural vector autoregressions (SVARs) and prior population versions of the same moments that are generated by habit and non-habit NKDSGE models. A NKDSGE model is evaluated by comparing its prior moments to the posterior moments. This comparison relies on the SVARs because these empirical models are used to compute the prior moments on a NKDSGE model's synthetic samples and posterior moments on the sample data.

We also study the impact various combinations of nominal frictions, monetary policy rules, and internal consumption habit have on NKDSGE model fit. Motivation is provided by Christiano, Eichenbaum, and Evans (CEE), Smets and Wouters (2007), and Dupor, Han, and Tsai (2009). CEE report that a money growth shock is transmitted by sticky wages, but not by sticky prices. In contrast, Smets and Wouters present evidence that sticky prices and wages have about the same effect on NKDSGE model fit given that monetary policy is a Taylor rule. However, Dupor, Han, and Tsai obtain estimates of a NKDSGE model identified by a productivity shock, instead of a Taylor rule shock, that point to

3. The MEI eschews estimation, but we recognize that estimating NKDSGE models with limited information estimators (LIEs) and classical and Bayesian likelihood methods is useful. Nonetheless, estimation does not guarantee problem free evaluation of NKDSGE models. For example, model misspecification is an issue for frequentists when evaluating NKDSGE models. Applying a LIE to an incorrectly specified NKDSGE model yields estimates that are not robust to changing identification (or instruments), as suggested by Dupor, Han, and Tsai (2009). A strength of Bayesian likelihood-based estimation is that it updates the priors of NKDSGE model parameters, which is absent from the MEI of Geweke. Not updating priors can produce misleading measures of model fit when these priors are badly constructed, but posterior distributions created by Bayesian likelihood-based estimation suffer similar problems from poorly formed priors as discussed by Poirier (1998). Given these issues, we view the MEI as providing analysis that complements studies that estimate NKDSGE models. 
flexible prices and durability in consumption rather than habit.

The Bayesian Monte Carlo experiments show that internal consumption habit improves the fit of the NKDSGE models to the posterior SDs of output and consumption growth. However, this fit is sensitive to (1) changes in the mix of nominal rigidities, (2) the choice of monetary policy rule, (3) matching SDs on permanent total factor productivity (TFP) shocks, and (4) using the entire spectrum rather than just the business cycle frequencies. These vulnerabilities reveal that the specification of NKDSGE models is fragile.

The rest of the paper is constructed as follows. Section 2 discusses internal consumption habit and NKDSGE models. Our approach to NKDSGE model evaluation is outlined in section 3. Results appear in section 4 . Section 5 concludes.

\section{INTERNAL CONSUMPTION HABIT AND NKDSGE MODELS}

This section describes household preferences with internal consumption habit, studies the internal consumption habit propagation mechanism, and sketches the baseline NKDSGE model.

\subsection{Internal consumption habit}

Internal habit operates on lagged household consumption, unlike external habit, which assumes that lags of aggregate consumption appear in utility; see Abel (1990). ${ }^{4}$ Household preferences are intertemporally separable and separable across (net) consumption flow, labor disutility, and real balances

$$
\mathcal{U}\left(c_{t}, c_{t-1}, n_{t}, \frac{H_{t}}{P_{t}}\right)=\ln \left[c_{t}-h c_{t-1}\right]-\frac{\gamma}{1+\gamma} n_{t}^{1+\frac{1}{\gamma}}+\ln \left[\frac{H_{t}}{P_{t}}\right]
$$

where $c_{t}, n_{t}, h, \gamma, H_{t}$, and $P_{t}$ are household consumption, household labor supply, the internal consumption habit parameter $h \in(0,1)$, the Frisch labor supply elasticity ( $\gamma>0)$, household cash at the end of date $t-1$, and the aggregate price level, respectively. Since internal consumption habit ties the choice of $c_{t}$ to $c_{t-1}$, the marginal utility of consumption is forward-looking,

$$
\lambda_{t}=\frac{1}{c_{t}-h c_{t-1}}-\mathbf{E}_{t}\left\{\frac{\beta h}{c_{t+1}-h c_{t}}\right\}
$$

assuming $0<c_{t}-h c_{t-1}$ for all $t$, where the household discount factor $\beta \in(0,1)$ and $\mathbf{E}_{t}\{\cdot\}$ is the mathematical expectation operator given date $t$ information.

4. The appendix shows there is an observational equivalence for multiplicative internal and external consumption habit using the onto mapping from additive to multiplicative consumption habit parameters that Dennis (2009) constructs. This indicates little generality is lost by focusing on internal consumption habit. The appendix is available at http://hermesir.lib.hit-u.ac.jp/rs/bitstream/10086/23297/1/070econDP12-08.pdf. 


\subsection{The internal consumption habit propagation mechanism}

Forward-looking marginal utility suggests internal habit acts as a propagation mechanism for consumption. Intuition about this propagation mechanism is grounded in the Euler equation

$$
\lambda_{t}=\beta \mathbf{E}_{t}\left\{\frac{\lambda_{t+1} R_{t+1}}{1+\varsigma_{t+1}}\right\}
$$

where $R_{t}$ is the nominal rate and $1+\varsigma_{t+1}\left(=P_{t+1} / P_{t}\right)$ is date $t+1$ inflation. ${ }^{5}$ A log linear approximation of the Euler equation and the marginal utility of consumption give a second order stochastic difference equation for demeaned consumption growth, $\widetilde{\Delta c}$, whose solution is

$$
\widetilde{\Delta c}=\varphi_{1} \widetilde{\Delta c}_{t-1}+\frac{\left(\alpha^{*}-\beta h\right)\left(\alpha^{*}-h\right)}{\alpha^{2} \varphi_{2}} \sum_{j=0}^{\infty} \varphi_{2}^{-j} \mathbf{E}_{t} \tilde{q}_{t+j},
$$

where the stable and unstable roots are $\varphi_{1}=h \alpha^{*-1}$ and $\varphi_{2}=\alpha^{*}(\beta h)^{-1}, \alpha^{*}$ is steady-state growth, the demeaned real interest rate is $\widetilde{q}_{t}=\widetilde{R}_{t}-\frac{\varsigma^{*}}{1+\varsigma^{*}} \widetilde{\zeta}_{t}$, and $\varsigma^{*}$ is mean inflation. ${ }^{6}$

Equation (2) yields the response of $\widetilde{\Delta c}$ to a shock in $\tilde{q}_{t}$ by calibrating it, $\beta$, and $\alpha^{*}$. The calibration to quarterly data sets $\tilde{q}_{t}$ to a first-order autoregression, $\operatorname{AR}(1)$, with AR1 coefficient $\rho_{q}=0.87$ and $\left[\beta \alpha^{*}\right]^{\prime}=[0.993 \exp (0.004)]^{\prime} .{ }^{7}$ Impulse response functions (IRFs) and SDs of $\widetilde{\Delta c}$ are produced using

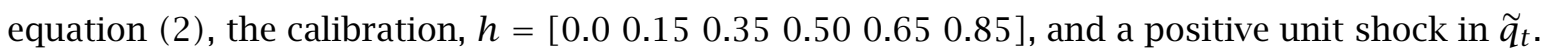

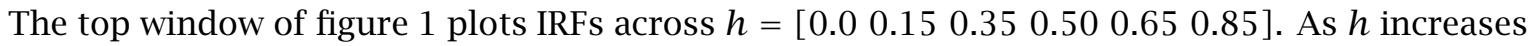
from 0.15 to 0.85 , IRFs become more humped shaped with the peak in $\widetilde{\Delta c_{t}}$ moving from a horizon of one quarter (the plain blue solid line) to quarter 6 (the purple solid line with the $\times$ symbol). Subsequently, $\widetilde{\Delta c} t$ steadily falls, but the decay rate slows as $h$ rises. These IRFs contrast with the IRF generated when household preferences are not infected by internal consumption habit. The top window of figure 1 depicts the latter IRF with a (black) solid line with the symbol $\diamond$. This IRF is not hump shaped and, because it is equivalent to the autocorrelation function of $\tilde{q}_{t}$, its slow decay is governed by powers of $\rho_{q} \cdot{ }^{8}$ Hence, internal habit by switching consumption from an intertemporal substitute at $h=0$ to a complement, given $h \in(0,1)$, creates an economically meaningful propagation mechanism.

5. Consumption-based asset pricing models with habit and local substitution through service are estimated by Eichenbaum and Hansen (1990) and Heaton (1995). They reject the adjustment cost hypothesis in favor of services flows. However, the data support habit if local substitutability operates at lower frequencies than the sampling frequency of consumption.

6. The appendix constructs equation (2), assuming a unit root TFP shock drives trend consumption. Also, $\widetilde{R}_{t}$ is the demeaned nominal federal funds rate, while $\varsigma_{t}$ is set to the growth rate of the implicit GDP deflator.

7. The SIC selects an AR(1) for $\tilde{q}_{t}$ over any lag length up to 10 on a 1954Q1-2002Q4 sample. See the appendix for details.

8. The equivalence stems from a linear approximate Euler equation under $h=0$ equating $\widetilde{\Delta c} t$ to $\tilde{q}_{t}$ up to an Euler error. 
This internal consumption habit propagation mechanism is similar to the one discussed by CEE using the NKDSGE models they estimate. Their baseline NKDSGE model, in which $h$ is estimated to be about 0.65 , generates a hump-shaped response in output that peaks 6 quarters after an innovation to a nominal shock. The top panel of figure 1 includes an IRF created using $h=0.65$, the (aquamarine) dot-dashed plot, that has similar dynamics with a peak at quarter 5. This shows that equation (2) can produce an IRF that resembles those found using estimated NKDSGE models.

Another way to understand the role of internal consumption habit in consumption growth dynamics is the $S D$ of $\widetilde{\Delta c}$. The $S D$ of $\widetilde{\Delta c}$, which we denote $S D_{\widetilde{\Delta c}}$, decomposes the variance of $\widetilde{\Delta c} t$ frequency by frequency. The bottom panel of figure 1 shows that the $S D s_{\widetilde{\Delta c}} \mathrm{~s}$ have the greatest power at the long run (i.e., frequency zero), which indicates that the lowest frequencies contribute most to the variance of $\widetilde{\Delta c}$. The $S D_{\widetilde{\Delta c}}$ indexed by no habit exhibits more power from frequency zero to about 4 years per cycle compared to the $S D_{\widetilde{\Delta c}}$ s driven by internal consumption habit. Over these frequencies, power declines monotonically for the $S D_{\widetilde{\Delta c}}$ as $h$ steps up from 0.15 to 0.85 . Thus, greater internal consumption habit lowers the power of $S D_{\widetilde{\Delta c}}$ s from the lowest to the business cycle frequencies.

To summarize, internal consumption habit makes it more costly for the household to smooth utility intertemporally. This dictates intertemporal complimentarity, which persuades the household to push the peak in its consumption growth response to a shock further into the future. These utility costs also produce $S D$ s with less power in the lower frequencies as $h$ rises. The rest of this paper uses this intuition to study the implications of internal consumption habit for NKDSGE models.

\subsection{A new Keynesian DSGE model}

Besides internal consumption habit, the baseline NKDSGE model contains ( $a$ ) capital adjustment costs, (b) variable capital utilization, (c) fully indexed Calvo-staggered wage setting by monopolistic households with heterogeneous labor supply, and $(d)$ fully indexed Calvo-staggered price setting by monopolistic final goods firms. Elements $(a)-(c)$ contribute to the optimization problems faced by households with addresses, $\ell \in[0,1]$, on the unit circle. The budget constraint of household $\ell$ is

$$
\frac{H_{t+1}}{P_{t}}+\frac{B_{t+1}}{P_{t}}+c_{t}+x_{t}+a\left(u_{t}\right) k_{t}+\tau_{t}=r_{t} u_{t} k_{t}+\frac{W_{t}(\ell)}{P_{t}} n_{t}(\ell)+\frac{H_{t}}{P_{t}}+R_{t} \frac{B_{t}}{P_{t}}+\frac{D_{t}}{P_{t}}
$$

where $B_{t+1}$ is the stock of government bonds carried from date $t$ into date $t+1, x_{t}$ is investment, $k_{t}$ is household capital at the end of date $t-1, \tau_{t}$ is a lump-sum government transfer, $r_{t}$ is the real rental rate 
of $k_{t}, W_{t}(\ell)$ is the nominal wage of household $\ell, R_{t}$ is the nominal return on $B_{t}, D_{t}$ is dividends received from firms, $u_{t} \in(0,1)$ is the capital utilization rate, and $a\left(u_{t}\right)$ is its cost function. A change in $u_{t}$ forces household $\ell$ to forgo $a(\cdot)$ units of consumption per unit of capital. The investment adjustment costs specification, which is adapted from CEE, is placed in the law of motion of household capital

$$
k_{t+1}=(1-\delta) k_{t}+\left[1-S\left(\frac{1}{\alpha} \frac{x_{t}}{x_{t-1}}\right)\right] x_{t}, \quad \delta \in(0,1), \quad 0<\alpha,
$$

where $\delta$ is the capital depreciation rate and $\alpha\left(=\ln \alpha^{*}\right)$ is deterministic TFP growth. The cost function $S(\cdot)$ is strictly convex, where $S(1)=S^{\prime}(1)=0$ and $S^{\prime \prime}(1) \equiv \varpi>0$.

Given $k_{0}, B_{0}$, and $c_{-1}$, the expected discounted lifetime utility function of household $\ell$

$$
\mathbf{E}_{t}\left\{\sum_{i=0}^{\infty} \beta^{i} \mathcal{U}\left(c_{t+i}, c_{t+i-1}, n_{t+i}(\ell), \frac{H_{t}}{P_{t}}\right)\right\}
$$

is maximized by choosing $c_{t}, k_{t+1}, H_{t+1}, B_{t+1}$, and $W_{t}(\ell)$ subject to period utility (1), budget constraint (3), the law of motion of capital (4), and downward sloping labor demand.

Households charge firms $W_{t}(\ell)$ per unit of differentiated labor services in a monopolistic market in which a Calvo-staggered nominal wage mechanism operates. Given $\theta$ is the wage elasticity, the labor supply aggregator is $N_{t}=\left[\int_{0}^{1} n_{t}(\ell)^{(\theta-1) / \theta} d \ell\right]^{\theta /(\theta-1)}$. Labor market monopoly imposes downward sloping labor demand schedules, $n_{t}(\ell)=\left[W_{t} / W_{t}(\ell)\right]^{\theta} N_{t}$, on firms, where the nominal wage index is $W_{t}=\left[\int_{0}^{1} W_{t}(\ell)^{1-\theta} d \ell\right]^{1 /(1-\theta)}$ and its aggregator is $W_{t}=\left[\left(1-\mu_{W}\right) W_{c, t}^{1-\theta}+\mu_{W}\left(\alpha^{*} \varsigma_{t-1} W_{t-1}\right)^{1-\theta}\right]^{1 /(1-\theta)}$. This Calvo-staggered nominal wage mechanism has households updating their nominal wage to $W_{c, t}$ at probability $1-\mu_{W}$. At probability $\mu_{W}$, households receive the date $t-1$ nominal wage indexed by steady-state TFP growth, $\alpha^{*}$, and $\varsigma_{t-1}$. In this case, the optimal nominal wage condition is

$$
\left[\frac{W_{c, t}}{P_{t-1}}\right]^{1+\theta / \gamma}=\left(\frac{\theta}{\theta-1}\right) \frac{\mathbf{E}_{t} \sum_{i=0}^{\infty}\left[\beta \mu_{W} \alpha^{*-\theta(1+1 / \gamma)}\right]^{i}\left[\left[\frac{W_{t+i}}{P_{t+i-1}}\right]^{\theta} N_{t+i}\right]^{1+1 / \gamma}}{\mathbf{E}_{t} \sum_{i=0}^{\infty}\left[\beta \mu_{W} \alpha^{*(1-\theta)}\right]^{i} \lambda_{t+i}\left[\frac{W_{t+i}}{P_{t+i-1}}\right]^{\theta}\left[\frac{P_{t+i}}{P_{t+i-1}}\right]^{-1} N_{t+i}} .
$$

Equation (6) smooths nominal wage growth, which forces labor supply to absorb TFP and monetary policy shocks. Since shifts in labor supply alter production and intra- and intertemporal margins, shock volatility and persistence are realized, for example, as output and consumption fluctuations.

Monopolistically competitive firms produce final goods that households consume. The consumption aggregator is $c_{t}=\left[\int_{0}^{1} y_{D, t}(j)^{(\xi-1) / \xi} d j\right]^{\xi /(\xi-1)}$, where $y_{D, t}(j)$ is household final good demand for 
the output of a firm with address $j$ on the unit interval. The $j$ th final good firm aims to meet this demand with its output, $y_{t}(j)$, by mixing capital, $K_{t}(j)$, rented and labor, $N_{t}(j)$, hired from households net of fixed cost $N_{0}$ given labor-augmenting TFP, $A_{t}$, in the constant returns to scale technology, $\left[u_{t} K_{t}(j)\right]^{\psi}\left[\left[N_{t}(j)-N_{0}\right] A_{t}\right]^{1-\psi}, \psi \in(0,1)$. Fixed labor cost $N_{0}$ satisfies the needs of monopolistic competition in the final goods market. For the NKDSGE model to have a permanent shock, TFP is a random walk with drift, $A_{t}=A_{t-1} \exp \left\{\alpha+\varepsilon_{t}\right\}$, with its innovation, $\varepsilon_{t} \sim \mathcal{N}\left(0, \sigma_{\varepsilon}^{2}\right)$.

Firm $j$ maximizes profits by choosing its price $P_{t}(j)$, subject to $y_{D, t}(j)=\left[P_{t} / P_{t}(j)\right]^{\xi} Y_{D, t}$, where $\xi$ is the price elasticity, $Y_{D, t}$ is aggregate demand, and the price index is $P_{t}=\left[\int_{0}^{1} P_{t}(j)^{1-\xi}\right]^{1 /(1-\xi)}$. Calvo-staggered price setting restricts a firm to update its optimal price $P_{c, t}$ at probability $1-\mu_{P}$. Or with probability $\mu_{P}$, firms are stuck with $P_{t-1}$ scaled by $\varsigma_{t-1}$, which defines the price aggregator $P_{t}=$ $\left[\left(1-\mu_{P}\right) P_{c, t}^{1-\xi}+\mu_{P}\left(\varsigma_{t-1} P_{t-1}\right)^{1-\xi}\right]^{1 /(1-\xi)}$. The firm's problem yields the optimal forward-looking price

$$
\frac{P_{c, t}}{P_{t-1}}=\left(\frac{\xi}{\xi-1}\right) \frac{\mathbf{E}_{t} \sum_{i=0}^{\infty}\left(\beta \mu_{P}\right)^{i} \lambda_{t+i} \phi_{t+i} Y_{D, t+i} \varsigma_{t+i}^{\xi}}{\mathbf{E}_{t} \sum_{i=0}^{\infty}\left(\beta \mu_{P}\right)^{i} \lambda_{t+i} Y_{D, t+i} \varsigma_{t+i}^{\xi-1}}
$$

of a firm able to update its price. Inflation is smoothed by equation (7). The same responses are induced in output and consumption in response to TFP and monetary policy shocks because of the reaction of monopolistically competitive firms to variation in the aggregate price level.

We close the NKDSGE model with one of two monetary policy rules. CEE identify monetary policy with a $\mathrm{MA}(\infty)$ money growth process. It is equivalent to the $\mathrm{AR}(1)$ money growth rule (MGR)

$$
m_{t+1}=\left(1-\rho_{m}\right) m^{*}+\rho_{m} m_{t}+\mu_{t}, \quad\left|\rho_{m}\right|<1, \quad \mu_{t} \sim \mathcal{N}\left(0, \sigma_{\mu}^{2}\right)
$$

where $m_{t+1}=\ln \left(M_{t+1} / M_{t}\right)$ and $m^{*}$ is its mean. A model using the MGR (8) is labeled NKDSGE-MGR. The mnemonic NKDSGE-TR refers to models closed by the Taylor rule (TR)

$$
\left(1-\rho_{R} \mathbf{L}\right) R_{t}=\left(1-\rho_{R}\right)\left(R^{*}+a_{\zeta} \mathbf{E}_{t} \zeta_{t+1}+a_{\tilde{Y}} \tilde{Y}_{t}\right)+v_{t}, \quad\left|\rho_{R}\right|<1, \quad v_{t} \sim \mathcal{N}\left(0, \sigma_{v}^{2}\right)
$$

where $R^{*}=\exp \left(m^{*}-\alpha\right) / \beta$. The TR (9) assumes the Taylor principle, $1<a_{\varsigma}$ is obeyed, $0<a_{\tilde{Y}}$, and expected inflation, $\mathbf{E}_{t} \varsigma_{t+1}$, and transitory output, $\tilde{Y}_{t}$, are computed without measurement errors.

The government finances $B_{t}$, interest on $B_{t}$, and a lump-sum transfer $\tau_{t}$ with new bond issuance $B_{t+1}-B_{t}$, lump-sum taxes $\tau_{t}$, and money creation, $M_{t+1}-M_{t}$. These sources and uses of funds give the 
government the budget constraint $P_{t} \tau_{t}=\left[M_{t+1}-M_{t}\right]+\left[B_{t+1}-\left(1+R_{t}\right) B_{t}\right]$. We assume government debt is in zero net supply, $B_{t+1}=0$ and $P_{t} \tau_{t}=M_{t+1}-M_{t}$, along the equilibrium path at all dates $t$.

The decentralized economy requires goods, labor, and money markets to clear in equilibrium. Equilibrium has $K_{t}=k_{t}$ given $0<r_{t}, N_{t}=n_{t}$ given $0<W_{t}$, and $M_{t}=H_{t}$ given $0<P_{t}, R_{t}$. The aggregate resource constraint, $Y_{t}=C_{t}+I_{t}+a\left(u_{t}\right) K_{t}$, follows, where $C_{t}=c_{t}$ and $I_{t}=x_{t}{ }^{9}$

\section{Bayesian Monte Carlo Strategy}

Population moments are used to judge the fit of 12 variants of the NKDSGE model. Bayesian Monte Carlo simulations are run that apply sample data, a structural vector moving average (SVMA), its priors, and a Markov chain Monte Carlo (MCMC) simulator to create posterior distributions of SDs of output growth, $\Delta Y$, and consumption growth, $\Delta C$. Prior distributions of $S D$ s of $\Delta Y$ and $\Delta C$ are approximated using a SVMA estimated on synthetic data that are simulated from NKDSGE models with parameters drawn from independent priors. The econometric link between the posterior and prior SDs and the sample data is the SVMAs. The multidimensional posterior and prior SDs are collapsed into scalar Kolmogorov-Smirnov $(K S)$ goodness of fit statistics to compute the confidence interval criterion (CIC) of DeJong, Ingram, and Whiteman (1996). A CIC measures the overlap of posterior and prior KS statistic distributions. We use the CIC to quantify the fit of the NKDSGE models.

\subsection{Output and consumption moments}

The NKDSGE models are evaluated on permanent and transitory SDs of $\Delta Y$ and $\Delta C$. The $S D s$ are grounded on SVMAs just-identified by the LRMN restriction embedded in the NKDSGE model and orthogonality of permanent and transitory shock innovations. Given these restrictions, the SVMAs are computed by applying the Blanchard and Quah (1989) decomposition to second-order VARs, VAR(2)s, of $\left[\Delta \ln Y_{t} \Delta \ln P_{t}\right]^{\prime}$ and $\left[\Delta \ln C_{t} \Delta \ln P_{t}\right]^{\prime}$. The Blanchard and Quah (BQ) decomposition identifies the SVMAs because the TFP innovation $\varepsilon_{t}$ is the permanent shock and the transitory shock is either the MGR innovation $\mu_{t}$ or TR innovation $v_{t} .{ }^{10}$ The identified $\Delta \ln Y_{t}-\Delta \ln P_{t}\left(\Delta \ln C_{t}-\Delta \ln P_{t}\right)$ system recovers a vertical long-run aggregate supply (PIH) curve and a serially correlated "output (consumption) gap."

\footnotetext{
9. A rational expectations equilibrium equates, on average, firm and household subjective forecasts of $r_{t}$, and $A_{t}$ to the objective outcomes produced by the decentralized economy. The list includes $\mu_{t}$ and $R_{t}$ under the MGR (8) or $v_{t}$ for the TR (9). A flexible price regime (spot labor market) adds $P_{t}\left(W_{t}\right)$.

10. The appendix of Blanchard and Quah (1989) includes a theorem that establishes necessary and sufficient conditions under which bivariate ARs identify the correct responses to a permanent shock and a transitory shock when truth is that there are several of these shocks. The BQ decomposition is satisfied, according to the theorem, when responses, say, of $\Delta Y$ and $\Delta P$ to permanent or transitory shocks are equivalent up to a scalar lag operator. Since the shocks found in NKDSGE models are often AR(1)s, the theorem predicts that adding these shocks to a NKDSGE model do not create spurious identification.
} 
As an example consider the SVMA

$$
\left[\begin{array}{c}
\Delta \ln Y_{t} \\
\Delta \ln P_{t}
\end{array}\right]=\sum_{j=0}^{\infty} \mathbb{B}_{j}\left[\begin{array}{c}
\varepsilon_{t-j} \\
v_{t-j}
\end{array}\right] \text {, where } \mathbb{B}_{j}=\left[\begin{array}{ll}
\mathbb{B}_{\Delta Y, \varepsilon, j} & \mathbb{B}_{\Delta Y, v, j} \\
\mathbb{B}_{\Delta P, \varepsilon, j} & \mathbb{B}_{\Delta P, v, j}
\end{array}\right],
$$

that equates the monetary policy shock with the innovation $v_{t}$ of the Taylor rule (9). Elements of $\mathbb{B}_{j}$ are just-identified by imposing $(i)$ orthogonality on $\varepsilon_{t}$ and $v_{t}$ and $(i i)$ the LRMN restriction $\mathbb{B}_{\Delta Y, v}(\mathbf{1})=0$ (i.e., $\ln Y_{t+j}$ is independent of $v_{t}$ at the infinite horizon, $j \rightarrow \infty$ ). These assumptions decompose the SVMA (10) into univariate SMA $(\infty) s, \mathbb{B}_{\Delta Y, \varepsilon}(\mathbf{L}) \varepsilon_{t}$ and $\mathbb{B}_{\Delta Y, u}(\mathbf{L}) v_{t}$, for $\Delta Y$. The former (latter) SMA( $\infty$ ) is the IRF of $\Delta Y$ with respect to the permanent shock $\varepsilon_{t}$ (transitory shock $v_{t}$ ).

We grab the SMA $(\infty)$ of $\mathbb{B}_{\Delta Y, \varepsilon}(\mathbf{L}) \varepsilon_{t}$ and $\mathbb{B}_{\Delta Y, v}(\mathbf{L}) v_{t}$ from the SVMA (10) to compute permanent and transitory $S D$ s of $\Delta Y$. Since the SVMA (10) is also a Wold representation of [ $\left.\Delta \ln Y_{t} \Delta \ln P_{t}\right]^{\prime}$, its $S D$ (at frequency $\omega$ ) is $S D_{\left[\begin{array}{ll}\Delta Y & \Delta P\end{array}\right]}(\omega)=(2 \pi)^{-1} \Gamma_{\left[\begin{array}{ll}\Delta Y & \Delta P\end{array}\right]} \exp (-i \omega)$, where $\Gamma_{\left[\begin{array}{ll}\Delta Y & \Delta P\end{array}\right]}(l)=\sum_{j=0}^{\infty} \mathbb{B}_{j} \mathbb{B}_{j-l}^{\prime}$. The convolution $\Gamma_{\left[\begin{array}{ll}\Delta Y & \Delta P\end{array}\right]}(l)$ is expanded at horizon $j$ to obtain

$$
\mathbb{B}_{j} \mathbb{B}_{j-l}^{\prime}=\left[\begin{array}{cc}
\mathbb{B}_{\Delta Y, \varepsilon, j} \mathbb{B}_{\Delta Y, \varepsilon, j-l}+\mathbb{B}_{\Delta Y, u, j} \mathbb{B}_{\Delta Y, u, j-l} & \mathbb{B}_{\Delta Y, \varepsilon, j} \mathbb{B}_{\Delta P, \varepsilon, j-l}+\mathbb{B}_{\Delta Y, u, j} \mathbb{B}_{\Delta P, v, j-l} \\
\mathbb{B}_{\Delta P, \varepsilon, j} \mathbb{B}_{\Delta Y, \varepsilon, j-l}+\mathbb{B}_{\Delta P, v, j} \mathbb{B}_{\Delta Y, u, j-l} & \mathbb{B}_{\Delta P, \varepsilon, j} \mathbb{B}_{\Delta P, \varepsilon, j-1}+\mathbb{B}_{\Delta P, v, j} \mathbb{B}_{\Delta P, v, j-l}
\end{array}\right] .
$$

The matrix's off-diagonal entries are elements of the cross-covariance function of $\Delta Y$ and $\Delta P$ and, therefore, map to co- and quad-spectra. The autocovariance function of $\Delta Y$ with respect to $\varepsilon_{t}\left(v_{t}\right)$ is the upper left diagonal, $\mathbb{B}_{\Delta Y, \varepsilon, j} \mathbb{B}_{\Delta Y, \varepsilon, j-l}\left(\mathbb{B}_{\Delta Y, u, j} \mathbb{B}_{\Delta Y, v, j-l}\right)$. We exploit the SMAs $\mathbb{B}_{\Delta Y, \varepsilon}(\mathbf{L}) \varepsilon_{t}$ and $\mathbb{B}_{\Delta Y, v}(\mathbf{L}) v_{t}$, that are along the diagonal, to parameterize permanent and transitory $S D$ s of $\Delta Y$ at frequency $\omega$

$$
S D_{\Delta Y, l}(\omega)=\frac{1}{2 \pi}\left|\mathbb{B}_{\Delta Y, l, 0}+\mathbb{B}_{\Delta Y, l, 1} e^{-i \omega}+\mathbb{B}_{\Delta Y, \iota, 2} e^{-i 2 \omega}+\ldots+\mathbb{B}_{\Delta Y, \iota, j} e^{-i j \omega}+\ldots\right|^{2}, \quad \iota=\varepsilon, v,
$$

given the BQ decomposition assumption that the structural shock innovations have unit variances. Before computing $S D_{\Delta Y, \iota}(\omega)$, we truncate its polynomial at $j=40$, or a 10-year horizon. ${ }^{11}$

\subsection{The moments to match: Mean posterior distributions}

We engage MCMC software of Geweke (1999) and McCausland (2004) to create posterior distributions of SVMAs. These posterior distributions consist of $\mathcal{J}=5000$ SVMA parameter vectors that are grounded on unrestricted VAR(2)s, LRMN, the BQ decomposition, priors, and a 1954Q1-2002Q4 sample ( $T=196)$ of $\Delta Y, \Delta C$, and $\pi_{t}$. These $\mathcal{J}$ vectors are used to calculate distributions of posterior permanent and transitory $S D$ s of $\Delta Y$ and $\Delta C$. We label these posterior moments $S D_{\mathcal{P}, \Delta Y}$ and $S D_{\mathcal{P}, \Delta C}$. 11. This approach to estimating SDs extends the ideas of Akaike (1969) and Parzen (1974). 


\subsection{Bayesian simulation methods II: Prior distributions}

It takes multiple steps to solve and simulate the NKDSGE models. Since these models have a permanent TFP shock, stochastic detrending of optimality and equilibrium conditions is needed before log-linearizing around deterministic steady states. We engage an algorithm of Sims (2002) to solve for log linear approximate equilibrium laws. Synthetic samples are created by feeding sequences of the shock innovations $\varepsilon_{t}$ and $\mu_{t}$ or $v_{t}$ into the equilibrium laws of motion given initial conditions and draws from the priors of NKDSGE model parameters. The appendix describes these procedures in detail.

Table 1 lists the priors of the NKDSGE models. These priors reflect our uncertainty about NKDSGE model parameters. For example, the first item listed in table 1 is the consumption habit parameter $h$. We give $h$ an uninformative prior that is drawn from a uniform distribution with end points 0.05 and 0.95 in table 1 . The uninformative prior reflects a belief that any $h \in[0.05,0.95]$ is as likely as another. Non-habit NKDSGE models are defined by the degenerate prior $h=0$.

Priors are also taken from earlier DSGE model studies. ${ }^{12}$ We set the means of the priors of $\left[\begin{array}{llll}\beta & \delta & \alpha & \psi\end{array}\right]^{\prime}=\left[\begin{array}{llll}0.9930 & 0.0200 & 0.0040 & 0.3500\end{array}\right]^{\prime}$ that are consistent with the Cogley and Nason (1995b) calibration. Uncertainty about $\left[\begin{array}{lllll}\beta & \gamma & \delta & \alpha & \psi\end{array}\right]^{\prime}$ is captured by 95 percent coverage intervals, which contain values in Nason and Cogley (1994) and Hall (1996). We equate the prior of the investment cost of adjustment parameter $\varpi$ to estimates reported by Bouakez, Cardia, and Ruge-Murcia (2005). ${ }^{13}$ The standard deviation of TFP shock innovations, $\sigma_{\varepsilon}$, is endowed with a uniform prior because the DSGE literature suggests that any draw from $[0.0070,0.0140]$ is equally likely. The source of the prior mean of the Frisch labor supply elasticity, $\gamma=1.55$, and its 95 percent coverage interval of $[0.5,2.6]$ is Kimmel and Kniesner (1998). They estimate labor supply functions on U.S. panel data.

There are 4 sticky price and wage parameters to calibrate. The prior means are $\left[\begin{array}{lll}\xi & \mu_{P} & \theta\end{array} \mu^{\prime}=\right.$ $\left[\begin{array}{llll}12.0 & 0.55 & 15.0 & 0.7\end{array}\right]^{\prime}$. The mean of $\xi$ implies a steady-state price markup, $\xi /(\xi-1)$, of 9 percent with a 95 percent coverage interval that runs from 5 to 33 percent. This coverage interval blankets estimates found in Basu and Fernald (1997) and CEE. More uncertainty surrounds the priors of $\mu_{P}, \theta$, and $\mu_{w}$. Sbordone (2002), Nason and Slotsve (2004), Lindé (2005), and CEE suggest a 95 percent coverage interval for $\mu_{P}$ of $[0.45,0.65]$. Likewise, a 95 percent coverage interval of [0.04, 0.25] suggests substantial uncertainty around the 7 percent prior mean household wage markup, $\theta /(\theta-1)$. The degenerate

12. Several priors are centered on sample means of the consumption-output ratio, labor input, federal funds rate, and inflation using the 1954Q1-2002Q4 sample. We also fix $N_{0}=0.1678$ and $r^{*}=1.0050$.

13. The capacity utilization rate, $u_{t}$, and its cost function, $a(\cdot)$, are fixed at the steady state, $u^{*}=1$ and $a(1)=0$. Determinate solutions are achieved by setting $a^{\prime \prime}(1) / a^{\prime}(1)=1.174$. 
mean of $\mu_{w}$ and its 95 percent coverage interval reveals stickier nominal wages than prices, as found by CEE and Rabanal and Rubio-Ramírez (2005), but we imbue it with greater uncertainty.

The money growth rule (8) is calibrated to estimates from a 1954Q1-2002Q4 sample of the monetary base. The point estimates are degenerate priors for $\left[\begin{array}{lll}m^{*} & \rho_{m} & \sigma_{\mu}\end{array}\right]^{\prime}=\left[\begin{array}{llll}0.011 & 0.628 & 0.006\end{array}\right]^{\prime}$. We give these prior means less precision than found for the sample estimates. For example, the lower end of the 95 percent coverage interval of $\rho_{m}$ is near 0.46. CEE note that $\rho_{m} \approx 0.5$ implies the AR(1) money growth rule (8) mimics the persistence of their MA( $\infty)$ money growth shock policy process.

The calibration of the interest rate rule (9) obeys the Taylor principle and $a_{y} \in(0,1)$. The degenerate prior of $a_{\pi}$ is 1.80 . We assign a small role to movements in transitory output, $\tilde{Y}$, with a prior mean of 0.05 for $a_{y}$. The 95 percent coverage intervals of $a_{\pi}$ and $a_{y}$ rely on estimates reported by Smets and Wouters (2007). The interest rate rule (9) is also calibrated to smooth $R_{t}$ given a prior mean of 0.65 and a 95 percent coverage interval of $[0.55,0.74]$ that incorporates estimates found in Guerron-Quintana (2010). Ireland (2001) is the source of the prior mean of the standard deviation of the monetary policy shock, $\sigma_{v}=0.0051$, and its 95 percent coverage interval, [0.0031, 0.0072]. We assume all shock innovations are uncorrelated at leads and lags (i.e., $\mathbf{E}\left\{\varepsilon_{t+i} v_{t+q}\right\}=0$, for all $i, q$ ).

Prior draws of NKDSGE model parameter are applied to its log linear approximation to generate a synthetic sample of length $\mathcal{M}=\mathcal{W} \times T$. We set $\mathcal{W}=5$ to approximate prior population distributions. After estimating VAR(2)s on these samples, LRMN and the BQ decomposition are applied to construct SVMAs. ${ }^{14}$ The SVMAs are employed to compute prior population permanent and transitory $S D$ s of $\Delta Y$ and $\Delta C$. Since our uncertainty about the theory - the parameters of the NKDSGE models - is embedded in these prior population moments, the subscript $\mathcal{T}$ is used to denote $S D_{\mathcal{T}, \Delta Y}$ and $S D_{\mathcal{T}, \Delta C}$.

\subsection{Measures of fit}

An intermediate step in measuring NKDSGE model fit is to construct a $K S$ goodness of fit statistic similar to one used by Cogley and Nason (1995a). They evaluate the fit of a RBC model fit to the $S D_{\Delta Y}$ with the $K S$. Since multidimensional $S D$ s are mapped into a scalar $K S$ statistic, it is an efficient metric for summarizing the information in SDs when conducting a model evaluation exercise.

Bayesian Monte Carlo experiments produce distributions of permanent and transitory $S D_{\mathcal{P}, \Delta Y}$, $S D_{\mathcal{P}, \Delta C}, S D_{\mathcal{T}, \Delta Y}$, and $S D_{\mathcal{T}, \Delta C}$. We convert the multidimensional $S D$ s into scalar posterior and prior $K S$ statistics, $K S_{\mathcal{P}}$ and $K S_{\mathcal{T}}$. The first step normalizes permanent and transitory $S D_{\mathcal{P}, \Delta Y}, S D_{\mathcal{P}, \Delta C}, S D_{\mathcal{T}, \Delta Y}$

14. The appendix constructs the map from SVAR to SVMA. The SVARs satisfy the invertibility condition of FernándezVillaverde, Rubio-Ramírez, Sargent, and Watson (2007) across all Bayesian Monte Carlo simulations of the 12 NKDSGE models. 
and $S D_{\mathcal{T}, \Delta C}$ on sample permanent and transitory $S D$ s of $\Delta Y$ or $\Delta C, \widehat{S D}_{\Delta Y}$ and $\widehat{S D}_{\Delta C}$. The sample $S D$ s are calculated using a SVMA estimated on the actual data with length $T$. Define the normalization $\mathcal{R}_{\mathcal{D}, j}(\omega)$ $=\widehat{S D}(\omega) / S D_{\mathcal{D}, j}(\omega)$ at replication $j$ and frequency $\omega$, where $\mathcal{D}=\mathcal{P}, \mathcal{T}$. Next, compute the partial sum $\mathcal{V}_{\mathcal{D}, j}(2 \pi q / \mathcal{H})=2 \pi \mathcal{H}^{-1} \sum_{\ell=1}^{q} \mathcal{R}_{\mathcal{D}, j}(2 \pi \ell / \mathcal{H})$, where $\mathcal{H}=T$ when $\mathcal{D}=\mathcal{P}$ and $\mathcal{H}=\mathcal{M}$ otherwise. The partial sums are used to construct the partial difference $\mathcal{B}_{\mathcal{D}, j}(\kappa)=0.5 \pi^{-1} \sqrt{2 \mathcal{H}}\left[\mathcal{V}_{\mathcal{D}, j}(\kappa \pi)-\kappa \mathcal{V}_{\mathcal{D}, j}(\pi)\right]$, where $\kappa \in[0,1]$ indicates $\mathcal{B}_{\mathcal{D}, j}(\kappa)$ is evaluated on the entire spectrum. The scalar $K S_{\mathcal{D}}$ statistic at replication $j$ is calculated as the maximal absolute value of $\mathcal{B}_{\mathcal{D}, j}(\kappa), K S_{\mathcal{D}, j}=\operatorname{Max}_{\kappa \in[0,1]}\left|\mathcal{B}_{\mathcal{D}, j}(\kappa)\right|$. Thus, a $K S_{\mathcal{P}, j}\left(K S_{\mathcal{T}, j}\right)$ statistic measures the distance between a $S D_{\mathcal{P}}\left(S D_{\mathcal{T}}\right)$ and $\widehat{S D}$.

We engage the $C I C$ to measure the fraction of $\mathcal{J}$ elements of a $K S_{\mathcal{T}}$ distribution that occupies an interval defined by lower and upper quantiles of the associated $K S_{\mathcal{P}}$ distribution at a $1-p$ percent confidence level. ${ }^{15}$ Suppose a habit NKDSGE model generates a distribution of the permanent $S D_{\mathcal{T}, \Delta Y}$ that fills this interval with more than 30 percent of its elements $(C I C>0.3)$, but the corresponding non-habit model does not ( $C I C \leq 0.3$ ). In this case (as DeJong, Ingram, and Whiteman (1996) imply in their analysis of RBC models), the habit NKDSGE model is a more plausible match to the permanent $S D_{\mathcal{P}, \Delta Y} \cdot{ }^{16}$ Note that this match requires the $S D_{\mathcal{T}}$ distribution to be "near" the $S D_{\mathcal{P}}$ distribution at several frequencies for a $K S_{\mathcal{T}}$ statistic distribution to cover more than 30 percent of the distribution of a $K S_{\mathcal{P}}$ statistics. Thus, a CIC constitutes a 'joint test' of NKDSGE model fit.

The $K S_{\mathcal{P}}$ and $K S_{\mathcal{T}}$ statistics are computed on the entire spectrum (i.e., the long- to the short-run) and the business cycle horizons of 8 to 2 years per cycle. By isolating the business cycle fluctuations, we build on an insight of Diebold, Ohanian, and Berkowitz (1998). They focus on the business cycle frequencies when model misspecification corrupts measurement of short- and long-run fluctuations. We address this issue by limiting $\kappa$ to frequencies between 8 and 2 years per cycle, $\kappa \in[0.064,0.25]$, when compiling $K S_{\mathcal{P}}$ and $K S_{\mathcal{T}}$ distributions. This mitigates discounting NKDSGE models that perform well at business cycle horizons, but poorly on lower growth and higher short-run frequencies.

\section{HABIT AND NON-HABIT NKDSGE MODEl EvAluATION}

Before evaluating the fit of the NKDSGE models to posterior permanent and transitory $S D_{\mathcal{P}, \Delta Y} \mathrm{~S}$

15. As in DeJong, Ingram, and Whiteman (1996), the $C I C$ of a $K S_{\mathcal{T}}$ statistic distribution is set to $\frac{1}{1-p} \int_{a}^{b} K S_{\mathcal{T}, j} d j$ for a $1-p$ percent confidence level, where $a(b)$ is the lower $0.5 p$ (upper $1-0.5 p$ ) quantile and is normalized by $1-p$ to equal $\int_{a}^{b} K S_{\mathcal{P}, j} d j$. 16. If the CIC of a NKDSGE model with internal consumption habit is larger than a NKDSGE model without it, the implication is that Bayes factor supports the former model. 
and $S D_{\mathcal{P}, \Delta C} \mathrm{~s}$, we study the means of these posterior moments. Figure 2 plots mean posterior permanent and transitory $S D_{\mathcal{P}, \Delta Y}$ and $S D_{\mathcal{P}, \Delta C}$. The mean $S D_{\mathcal{P}, \Delta Y}\left(S D_{\mathcal{P}, \Delta C}\right)$ decomposes variation in the average response of $\Delta Y(\Delta C)$ to permanent and transitory shocks frequency by frequency. ${ }^{17}$ The top (bottom) panel of figure 2 contains mean permanent (transitory) $S D_{\mathcal{P}, \Delta Y}$ and $S D_{\mathcal{P}, \Delta C}$. Mean $S D_{\mathcal{P}, \Delta Y}$ appear as solid (blue) lines in figure 2 and mean $S D_{\mathcal{P}, \Delta C}$ are depicted with (blue) ' ' symbols.

Mean permanent $S D_{\mathcal{P}, \Delta Y}$ and $S D_{\mathcal{P}, \Delta C}$ display the greatest power at frequency zero in the top panel of figure 2. Subsequently, these $S D$ s decay from the growth (i.e., more than 8 years per cycle) into the highest frequencies (i.e., less than 2 years per cycle), which indicate these frequencies matter less and less for variation in the permanent components of $\Delta Y$ and $\Delta C$. Compared to the $S D_{\mathcal{P}, \Delta C}$, the mean permanent $S D_{\mathcal{P}, \Delta Y}$ exhibits about five times the power at the long run. This is consistent with the PIH and other business cycle theories that predict greater volatility in $\Delta Y$ than in $\Delta C$. However, the $\mathrm{PIH}$ is not supported by the mean permanent $S D_{\mathcal{P}, \Delta C}$ because it is not flat across the entire spectrum.

The lower panel of figure 2 presents mean transitory $S D_{\mathcal{P}, \Delta Y}$ and $S D_{\mathcal{P}, \Delta C}$ with disparate shapes. The latter $S D$ peaks around six years per cycle. Rather than a peak, the mean transitory $S D_{\mathcal{P}, \Delta C}$ plateaus from the growth frequencies to four years per cycle before dropping off in the high frequencies. Thus, the transitory or "output gap" component of $\Delta Y$ exhibits greater periodicity in the business cycle frequencies compared to the transitory component of $\Delta C$.

Figure 2 summarizes the challenge for NKDSGE models. The models must produce permanent $S D_{\mathcal{T}, \Delta Y}$ and $S D_{\mathcal{T}, \Delta C}$ that are not white noise, but instead have most power at the lowest frequencies, to match the permanent $S D_{\mathcal{P}}$ S displayed in the top panel of figure 2. The lower panel of figure 2 challenges NKDSGE models to generate transitory $S D_{\mathcal{T}, \Delta Y}\left(S D_{\mathcal{T}, \Delta C}\right)$ with the greatest power at the business cycle (growth) frequencies. As a result, NKDSGE models need empirically and economically meaningful propagation and monetary transmission mechanisms to match permanent and transitory $S D_{\mathcal{P}}$.

\subsection{Quantifying NKDSGE model fit: CIC}

Table 2 presents $C I C$ that measures the overlap of distributions of $K S_{\mathcal{P}}$ and $K S_{\mathcal{T}}$ statistics. The CIC is calculated at a 95 percent confidence level, $p=0.05$. The overlap of these distributions gauges the fit of 12 NKDSGE models to permanent and transitory $S D_{\mathcal{P}, \Delta Y}$ and $S D_{\mathcal{P}, \Delta C}$ distributions.

The 12 NKDSGE models are defined by different combinations of nominal frictions as well as by monetary policy rule. The first NKDSGE model is our baseline that includes sticky prices and wages. 17. A mean $S D_{\mathcal{P}}$ is computed across an ensemble of $S D_{\mathcal{P}, j}, j=1, \ldots, \mathcal{J}$, pointwise or frequency by frequency. 
From this baseline, two more NKDSGE models are created by stripping out one or the other nominal rigidity. ${ }^{18}$ Baseline, sticky price (SPrice), and sticky wage (SWage) NKDSGE models have household preferences with either no consumption habit, $h=0$, or internal consumption habit, $h \in[0.05,0.95]$. These six NKDSGE models are doubled by defining monetary policy with the MGR (8) or the TR (9).

The CIC of baseline, SPrice, and SWage non-habit NKDSGE models is listed in the top panel of table 2. The lower panel contains CIC of habit NKDSGE models. The NKDSGE-MGR and NKDSGE-TR models define monetary policy with the MGR (8) and the TR (9), respectively. Columns titled $[0, \pi]$ and $[8,2]$ report $C I C$ quantifying the overlap of distributions of $K S_{\mathcal{P}}$ and $K S_{\mathcal{T}}$ statistics on the entire frequency domain (i.e., the long-run or frequency zero to the short-run) and the business cycle frequencies that run from 8 to 2 years per cycle, respectively.

Table 2 contains CIC that indicates internal consumption habit improves the fit of NKDSGE models. Habit NKDSGE models generate 18 CIC > 0.3 (or 37.5 percent) out of a possible 48 in the bottom half of table 2, but the top half of the table shows that non-habit NKDSGE models are responsible for only 9 CIC $>0.3$ (or 18.75 percent). Thus, internal consumption habit contributes to permanent and transitory $S D_{\mathcal{T}, \Delta Y}$ and $S D_{\mathcal{T}, \Delta C}$ that better replicate the posterior moments.

A striking feature of table 2 is the impact of the monetary policy rules on the fit of NKDSGE models to transitory $S D_{\mathcal{P}, \Delta Y}$ and $S D_{\mathcal{P}, \Delta C}$. In these models, the MGR (8) has few successes at transmitting its shock innovation $\mu_{t}$ into $\Delta Y$ and $\Delta C$ fluctuations that resemble the posterior moments. According to the CIC of table 2, only the SPrice habit NKDSGE-MGR model accomplishes this task and only on the business cycle frequencies of 8 to 2 years per cycle.

The TR (9) improves NKDSGE model fit compared to the MGR (8). Of the 27 CIC $>0.3$ found in table 2, the TR (9) is tied to 22. In the top half of table 2, 8 of the 9 CIC $>0.3$ are generated by non-habit NKDSGE-TR models. Similarly, habit NKDSGE-TR models yield 14 of the 18 CIC $>0.3$ in the bottom half of table 2. Table 2 also indicates that, on the business cycle frequencies of 8 to 2 years per cycle, habit and non-habit NKDSGE-TR models match transitory $S D_{\mathcal{P}, \Delta Y}$ and $S D_{\mathcal{P}, \Delta C}$ with $C I C>0.3$ in all 12 possible cases. Thus, table 2 gives evidence that habit and non-habit NKDSGE models have empirically useful monetary transmission mechanisms when initiated by the TR shock innovation $v_{t}$. However, only habit NKDSGE-TR models are able to replicate the transitory $S D_{\mathcal{P}} S$ on the entire spectrum because

18. The sticky wage NKDSGE model requires the degenerate prior $\mu_{P}=0$ with fixed markup $\phi=(\xi-1) / \xi$. When the nominal wage is flexible, households set their optimal wage period by period in sticky price NKDSGE models. In this case, the markup in the labor market is fixed at $(\theta-1) / \theta$, which equals $n^{-1 / \gamma}$, given $\mu_{W}=0$. 
these models are responsible for 11 of 12 possible $C I C>0.33$ in the bottom half of table 2 .

The propagation mechanisms of the NKDSGE models are not held in similar regard by the permanent $S D_{\mathcal{P}, \Delta Y}$ and $S D_{\mathcal{P}, \Delta C}$. These $S D_{\mathcal{P}}$ S are matched only when permanent $S D_{\mathcal{T}, \Delta Y}$ and $S D_{\mathcal{T}, \Delta C}$ are generated by SPrice habit and non-habit NKDSGE-MGR and -TR models. The bottom half of table 2 shows that a CIC $>0.3$ appears in four of the four possible cases when SPrice habit NKDSGE-MGR and -TR models are asked to propagate the TFP innovation shock $\varepsilon_{t}$ into the business cycle frequencies of 8 to 2 years per cycle. The SPrice non-habit NKDSGE-MGR and -TR models are less successful at this task. Only the permanent $S D_{\mathcal{P}, \Delta Y}$ is duplicated by these models. When the propagation mechanisms of these models are examined using the entire spectrum, a $C I C>0.3$ is produced only for the permanent $S D_{\mathcal{P}, \Delta Y}$. Nontheless, this shows that measuring model fit on the entire spectrum leads to otherwise empirically relevant NKDSGE models being undervalued.

In summary, internal consumption habit confers a superior fit on NKDSGE models according to the CIC of table 2. The improved fit of habit NKDSGE models is predicated, in part, on the TR (9), but non-habit NKDSGE-TR models possess empirically and economically credible monetary transmission mechanisms when asked to match transitory $S D_{\mathcal{P}}$ S only on the business cycle frequencies of 8 to 2 years per cycle. Limiting the analysis to the business cycle frequencies improves the fit of SPrice habit NKDSGE-MGR and -TR models when the match is to permanent $S D_{\mathcal{P}, \Delta Y}$ and $S D_{\mathcal{P}, \Delta C} \cdot{ }^{19}$

\subsection{NKDSGE model dynamics: Internal consumption habit}

The habit NKDSGE models provide a superior fit to the permanent and transitory $S D_{\mathcal{P}, \Delta Y}$ s and $S D_{\mathcal{P}, \Delta C} \mathrm{~s}$, according to the $C I C$ of table 2. Although moment matching is useful for assessing the fit of the NKDSGE models, this evaluation process is not informative about the propagation and monetary transmission mechanism dynamics of NKDSGE models. This section and the next explores NKDSGE model dynamics by comparing mean permanent and transitory $S D_{\mathcal{P}} \mathrm{s}$ and $S D_{\mathcal{T}} \mathrm{s}$.

We summarize evidence about NKDSGE model dynamics in figures 3, 4, and 5 . The figures consist of four rows and two columns of panels containing means of $S D_{\mathcal{P}} \mathrm{S}$ and $S D_{\mathcal{T}} \mathrm{s}$. From top to bottom, the rows of figures 3-5 plot mean permanent $S D_{\Delta Y} \mathrm{~s}$, transitory $S D_{\Delta Y}$ s, permanent $S D_{\Delta C} \mathrm{~s}$, and transitory $S D_{\Delta C} \mathrm{~s}$. The NKDSGE-MGR models are responsible for $S D_{\mathcal{T}} \mathrm{s}$ that appear in the left column of

19. The appendix reports results of Bayesian Monte Carlo experiments that substitute the Cramer-von Mises goodness of fit statistic for the $K S$ statistic to quantify NKDSGE model fit, estimate VAR(4)s instead of VAR(2)s, and replace the uniform prior, $h \sim U(0.05,0.95)$, with either $h \sim U(0.05,0.499), h \sim U(0.50,0.95)$, or $h \sim \beta(0.65,0.15)$. The latter prior implies a 95 percent coverage interval for $h$ of $[0.38,0.88]$. These experiments reinforce the message table 2 has for the impact of internal consumption habit on NKDSGE model fit as well the vulnerabilities in the fit of NKDSGE models under different combinations of the nominal frictions and monetary policy rules. 
figures 3-5. The right column of these figures present $S D_{\mathcal{T}} \mathrm{s}$ that are generated by NKDSGE-TR models. Figures 3-5 display mean $S D_{\mathcal{P}}$ s with solid (blue) lines, mean $S D_{\mathcal{T}}$ s created by non-habit NKDSGE models with (green) dotted lines, and mean $S D_{\mathcal{T}}$ s tied to habit NKDSGE models with (red) dot-dashed lines. The mean $S D_{\mathcal{T}}$ s of baseline, SPrice, and SWage NKDSGE models are depicted in figures 3, 4, and 5, respectively.

Figures 3-5 display mean permanent and transitory $S D_{\mathcal{T}, \Delta Y} \mathrm{~s}$ and $S D_{\mathcal{T}, \Delta C} \mathrm{~s}$, with (green) dotted plots in figures 3-5, produced by non-habit NKDSGE models that often exhibit greater power than the (red) dot-dash mean $S D_{\mathcal{T}}$ s created by habit NKDSGE models. As a result, habit NKDSGE models generate $S D_{\mathcal{T}} \mathrm{s}$ that are either closer to or intersect mean $S D_{\mathcal{P}} \mathrm{S}$, especially at the business cycle frequencies.

These mean $S D_{\mathcal{T}}$ s reproduce an important feature of the $S D_{\widetilde{\Delta C}}$ plotted in the bottom window of figure 1. Remember the $S D_{\widetilde{\Delta C}}$ are computed using the linear approximate Euler equation (2) and from top to bottom are indexed by $h=0$ to 0.85 . The bottom window of figure 1 shows the $S D_{\widetilde{\Delta C}}$ s converge pointwise to the horizontal axis as $h$ increases. Since the mean permanent and transitory $S D_{\mathcal{T}, \Delta Y} \mathrm{~s}$ and $S D_{\mathcal{T}, \Delta C}$ s of figures 3-5 often have the same ordering, the utility adjustment costs inherent in internal consumption habit are responsible, in part, for propagation and monetary transmission in NKDSGE models that replicate the mean permanent and transitory $S D_{\mathcal{P}, \Delta Y} \mathrm{~s}$ and $S D_{\mathcal{P}, \Delta C} \mathrm{~s}$ of figure 2.

\subsection{NKDSGE model dynamics: Mixing nominal frictions and monetary policy rules}

This section explores the impact that different combinations of sticky prices, sticky wages, and monetary policy rule have on propagation and monetary transmission in NKDSGE models. For example, the first and third rows of figures 3-5 establish that there is no mix of nominal rigidities and monetary policy rule in either habit or non-habit NKDSGE models that produce a credible facsimile of the mean permanent $S D_{\mathcal{P}, \Delta Y}$ and $S D_{\mathcal{P}, \Delta C}$. The large gaps between these posterior moments and mean permanent $S D_{\mathcal{T}, \Delta Y}$ and $S D_{\mathcal{T}, \Delta C} \mathrm{~S}$ are not because the NKDSGE models lack powerful propagation mechanisms. Instead, the top row of windows of figures 3-5 reveal the 12 NKDSGE models propagate the TFP shock innovation $\varepsilon_{t}$ into $S D_{\mathcal{T}, \Delta Y}$ that often have greatest variation in the business cycle frequencies between 8 and 4 years per cycle. In comparison, the mean permanent $S D_{\mathcal{P}, \Delta Y}$ has greatest power at the long run before dropping off in the business cycle frequencies. Similarly, the third row of figures 3-5 displays large gaps between the $S D_{\mathcal{P}, \Delta C}$ and $S D_{\mathcal{T}, \Delta C}$.

The mean transitory $S D_{\mathcal{T}, \Delta Y}$ and $S D_{\mathcal{T}, \Delta C}$ of figures 3-5 show that the impact of inflation smoothing implied by the optimal forward-looking price setting of equation (7) contributes, along with internal 
consumption habit and the TR (9), to economically credible monetary transmission. This is the SPrice habit NKDSGE model whose mean transitory $S D_{\mathcal{T}, \Delta Y}$ and $S D_{\mathcal{T}, \Delta C}$ are depicted with (red) dot-dash plots in the even numbered rows of figure 4's right-hand column. Observe in the second row of figure 4 that the mean $S D_{\mathcal{T}, \Delta Y}$ peaks between 8 and 4 years per cycle, which echoes the shape of the mean transitory $S D_{\mathcal{P}, \Delta Y}$. The SPrice habit NKDSGE model also generates a mean transitory $S D_{\mathcal{T}, \Delta C}$ in the bottom right window of figure 4 that reproduces the plateau in the growth frequencies of the mean transitory $S D_{\mathcal{P}, \Delta C}$. The left-hand column of Figure 4 shows that dropping internal consumption habit or swapping the MGR (8) for the TR (9) pushes mean transitory $S D_{\mathcal{T}} \mathrm{s}$ away from the mean posterior moments.

There is no NKDSGE with nominal wage smoothing generated by the optimal nominal wage equation (6) that provides an economically meaningful monetary transmission mechanism. Figures 3 and 5 are clear that habit and non-habit NKDSGE models with sticky wages have difficulties reproducing mean transitory $S D_{\mathcal{P}, \Delta Y}$ and $S D_{\mathcal{P}, \Delta C}$. The baseline and SWage habit and non-habit NKDSGE models often generate power in mean transitory $S D_{\mathcal{T}, \Delta Y} \mathrm{~S}$ and $S D_{\mathcal{T}, \Delta C} \mathrm{~S}$ at the business cycle frequencies from 8 to 2 years a cycle, which is excessive compared to the mean transitory $S D_{\mathcal{T}, \Delta Y} \mathrm{~s}$ and $S D_{\mathcal{T}, \Delta C} \mathrm{~s}$. The distance between $S D_{\mathcal{P}} \mathrm{s}$ and $S D_{\mathcal{T}} \mathrm{s}$ is repaired only in part by switching from the MGR (8) to the TR (9) in baseline and SWage NKDSGE models. However, the bottom right window of figure 3 reports that the baseline habit NKDSGE-TR model generates a mean transitory $S D_{\mathcal{T}, \Delta C}$ with less power in the business frequencies, which moves it closer to the $S D_{\mathcal{P}, \Delta C} \mathrm{~s}$.

\section{Conclusion}

This paper studies the business cycle implications of internal consumption habit for NKDSGE models. We examine the fit of 12 NKDSGE models that have different combinations of internal consumption habit, Calvo-staggered prices, and nominal wages, along with several other real rigidities. The NKDSGE models are confronted with posterior SDs of output and consumption growth identified by permanent TFP and transitory monetary policy shocks.

The fit of NKDSGE models with and without internal consumption habit is explored by comparing posterior population moments to theoretical prior population moments. Our analysis shows that the fit of NKDSGE models with consumption habit is susceptible to (1) changing the mix of nominal rigidities, (2) identifying SDs on permanent TFP shocks instead of transitory monetary policy shocks, and (3) evaluating $S D$ s on the entire spectrum rather than the business cycle frequencies. 
These results indicate that there are vulnerabilities in the specification of NKDSGE models. Not unexpectedly, the new Keynesian monetary transmission mechanism is not the issue. There are combinations of sticky prices, sticky wages, and monetary policy rule that matches the posterior SDs of output and consumption growth. Nonetheless, only when internal consumption habit, sticky prices, and a Taylor rule are included in a NKDSGE model, does it transmit monetary policy shocks into empirically plausible mean SDs of output and consumption growth. The vulnerabilities in NKDSGE model fit are tied to the mix of nominal rigidities and judging fit on the entire spectrum when the moment matching exercise is identified with the permanent TFP shock. Thus, the economic and empirical relevance of the propagation mechanisms of NKDSGE models remains open to more research. We hope this paper plays a part in inspiring further research into the role real and nominal rigidities play in propagation as well as monetary transmission in NKDSGE models.

\section{References}

Abel, Andrew B. (1990) “Asset Prices Under Habit Formation and Catching Up with the Joneses." American Economic Review Paper and Proceedings, 80, 38-42.

Akaike, Hirotugu. (1969) "Power Spectrum Estimation Through Autoregressive Model Fitting." Annals of the Institute of Statistical Mathematics, 21, 407-419.

Basu, Susanto, and John G. Fernald. (1997) "Returns to Scale in U.S. Production: Estimates and Implications." Journal of Political Economy, 105, 249-283.

Blanchard, Olivier J., and Danny Quah. (1989). "The Dynamic Effects of Aggregate Demand and Supply Disturbances.” American Economic Review, 79, 655-673.

Boldrin, Michele, Lawrence Christiano, Jonas D.M. Fisher (2001). "Habit Persistence, Asset Returns, and the Business Cycle.” American Economic Review 91, 149-166.

Bouakez, Hafedh, Emanuela Cardia, and Francisco Ruge-Murcia. (2005) "Habit Formation and the Persistence of Monetary Policy Shocks.” Journal of Monetary Economics, 52, 1073-1088.

Christiano, Lawerence, Martin Eichenbaum, Charles L. Evans. (2005) "Nominal Rigidities and the Dynamic Effects of a Shock to Monetary Policy." Journal of Political Economy, 113, 1-45.

Cogley, Tim, and James M. Nason. (1995a) "Effects of the Hodrick-Prescott Filter on Trend and Difference Stationary Time Series: Implications for Business Cycle Research." Journal of Economic Dynamics and Control, 19, 253-278.

Cogley, Tim, and James M. Nason. (1995b) “Output Dynamics in Real-Business-Cycle Models.” American Economic Review, 85, 492-511.

Constantinides, George M. (1990) "Habit Formation: A Resolution of the Equity Premium Puzzle," Journal of Political Economy, 98, 519-543.

DeJong, David N., Beth F. Ingram, Charles H. Whiteman. (1996) “A Bayesian Approach to Calibration.” Journal of Business and Economic Statistics, 14, 1-9. 
Del Negro, Marco, Frank Schorfheide, Frank Smets, and Raf Wouters. (2007) "On the Fit of New Keynesian Models." Journal of Business and Economic Statistics, 25, 123-143.

Dennis, Richard. (2009) “Consumption-Habits in a New Keynesian Business Cycle Model.” Journal of Money, Credit and Banking, 41, 1015-1030.

Diebold, Francis X., Lee E. Ohanian, and Jeremy Berkowitz. (1998) "Dynamic Equilibrium Economies: A Framework for Comparing Models and Data." Review of Economic Studies 65, 433-451.

Dupor, Bill, Jing Han, and Yi-Chan Tsai. (2009) "What Do Technology Shocks Tell Us About the New Keynesian Paradigm?” Journal of Monetary Economics, 56, 560-569.

Eichenbaum, Martin, and Lars P. Hansen. (1990) "Estimating Models with Intertemporal Substitution Using Aggregate Time Series Data." Journal of Business and Economic Statistics, 8, 53-69.

Fernández-Villaverde, Jesus, Juan F. Rubio-Ramírez, Thomas J. Sargent, and Mark W. Watson. (2007) “ABC’s (and D)'s for Understanding VARS.” American Economic Review, 97, 1021-1026.

Galí, Jordi. (1991) “Budget Constraints and Time-Series Evidence on Consumption.” American Economic Review, 81, 1238-1253.

Geweke, John. (2010) Complete and Incomplete Econometric Models, Princeton, NJ: Princeton University Press.

Geweke, John. (1999) "Using Simulation Methods for Bayesian Econometric Models: Inference, Development, Communication." Econometric Reviews, 18, 1-73.

Guerron-Quintana, Pablo A. (2010) "What You Match Does Matter: The Effects of Data on DSGE Estimation." Journal of Applied Econometrics, 25, 774-804.

Hall, George J. (1996) “Overtime, Effort, and the Propagation of Business Cycle Shocks.” Journal of Monetary Economics, 38, 139-160.

Heaton, John. (1995) “An Empirical Investigation of Asset Pricing with Temporary Dependent Preference Specifications.” Econometrica, 63, 681-717.

Ireland, Peter N. (2001) "Sticky-price Models of the Business Cycle: Specification and Stability." Journal of Monetary Economics, 47, 3-18.

Kano, Takashi. (2009) "Habit Formation, and the Present-value Model of the Current Account: Yet Another Suspect." Journal of International Economics, 78, 72-85.

Kimmel, Jean, and Thomas J. Kniesner. (1998) "New Evidence on Labor Supply: Employment versus Hours Elasticities by Sex and Marital Status.” Journal of Monetary Economics 42, 289-301.

Lindé, Jesper. (2005) "Estimating New-Keynesian Phillips Curves: A Full Information Maximum Likelihood Approach." Journal of Monetary Economics, 52, 1135-1149.

McCausland, William. (2004) "Using the BACC Software for Bayesian Inference." Journal of Computational Economics, 23, 201-218.

Nason, James M. (1988) “The Equity Premium and Time-varying Risk Behavior.” FEDS Paper no. 11, Board of Governors of the Federal Reserve System, Washington, DC.

Nason, James M. (1997) “Taste Shocks.” In Business Cycles and Depressions: An Encyclopedia, edited by David Glaser, pp. 673-676. New York, NY: Garland Publishing.

Nason, James M., and Tim Cogley. (1994) "Testing the Implications of Long-run Neutrality for Monetary Business Cycle Models." Journal of Applied Econometrics, 9, S37-S70. 
Nason, James M., and John H. Rogers. (2006) "The Present-Value Model of the Current Account Has Been Rejected: Round up the Usual Suspects.” Journal of International Economics, 68, 159-187.

Nason, James M., and George A. Slotsve. (2004) "Along the New Keynesian Phillips Curve with Nominal and Real Rigidities.” Working Paper 2004-09, Federal Reserve Bank of Atlanta.

Otrok, Christopher, B. Ravikumar, and Charles H. Whiteman. (2002) "Habit Formation: A Resolution of the Equity Premium Puzzle.” Journal of Monetary Economics 49, 1261-1288.

Parzen, Emanuel. (1974) "Some Recent Advances in Time Series Modelling." I.E.E.E. Transactions on Automatic Control, AC-19, 723-729.

Poirier, Dale J. (1998) "Revising Beliefs in Nonidentified Models." Econometric Theory, 14, 483-509.

Pollak, Robert A. (1976) "Habit Formation and Long-run Utility Functions.” Journal of Economic Theory, $13,272-297$.

Rabanal, Pau, and Juan F. Rubio-Ramírez. (2005) "Comparing New Keynesian Models of the Business Cycle: A Bayesian Approach.” Journal of Monetary Economics, 52, 1151-1166.

Rozen, Kareen. (2010) "Foundations of Intrinsic Habit Formation.” Econometrica, 78, 1341-1373.

Ryder, Harl E., Jr., and Geoffrey M. Heal. (1973) "Optimal Growth with Intertemporally Dependent Preferences." Review of Economic Studies, 40, 1-31.

Sbordone, Argia M. (2002) "Prices and Unit Costs: A New Test of Price Stickiness.” Journal of Monetary Economics, 49, 235-456.

Sims, Christopher A. (2002) "Solving Linear Rational Expectations Models." Computational Economics, $20,1-20$.

Schmitt-Grohé, Stephanie, and Martin Uribe. (2007) "Habit Persistence.” In The New Palgrave Dictionary of Economics, second edition, edited by Steven N. Durlauf and Lawerence Blume, New York, NY: Palgrave Macmillan.

Smets, Frank, and Raf Wouters. (2007) "Shocks and Frictions in US Business Cycles: A Bayesian DSGE approach.” American Economic Review, 97, 1123-1175.

Sundaresan, Suresh. (1989) "Intertemporally Dependent Preferences and the Volatility of Consumption and Wealth.” Review of Financial Studies, 2, 73-89. 


\section{TABLE 1: BAYESIAN CALIBRATION OF NKDSGE MODELS}

\begin{tabular}{|c|c|c|c|c|c|}
\hline & & $\begin{array}{c}\text { Prior } \\
\text { Distribution }\end{array}$ & Mean & $\begin{array}{l}\text { Standard } \\
\text { Deviation }\end{array}$ & $\begin{array}{c}95 \text { Percent } \\
\text { Cover Interval }\end{array}$ \\
\hline$h$ & Internal Consumption Habit & Uniform & - & - & {$[0.0500,0.9500]$} \\
\hline$\beta$ & H'hold Subjective Discount & Beta & 0.9930 & 0.0020 & {$[0.9886,0.9964]$} \\
\hline$\gamma$ & Labor Supply Elasticity & Normal & 1.5500 & 0.5360 & {$[0.4995,2.6005]$} \\
\hline$\delta$ & Depreciation Rate & Beta & 0.0200 & 0.0045 & {$[0.0122,0.0297]$} \\
\hline$\alpha$ & Deterministic Growth Rate & Normal & 0.0040 & 0.0015 & {$[0.0011,0.0064]$} \\
\hline$\varpi$ & Capital Adjustment Costs & Normal & 4.7710 & 1.0260 & {$[2.7601,6.7819]$} \\
\hline$\psi$ & Capital's Share of Output & Beta & 0.3500 & 0.0500 & {$[0.2554,0.4509]$} \\
\hline$\sigma_{\varepsilon}$ & TFP Growth Shock Std. & Uniform & - & - & {$[0.0070,0.0140]$} \\
\hline$\xi$ & Final Good Dmd Elasticity & Normal & 12.0000 & 4.0820 & {$[3.9994,20.0006]$} \\
\hline$\mu_{P}$ & No Price Change Probability & Beta & 0.5500 & 0.0500 & {$[0.4513,0.6468]$} \\
\hline$\theta$ & Labor Demand Elasticity & Normal & 15.0000 & 3.0800 & {$[8.9633,21.0367]$} \\
\hline$\mu_{W}$ & No Wage Change Probability & Beta & 0.7000 & 0.0500 & {$[0.5978,0.7931]$} \\
\hline$m^{*}$ & $\Delta \ln M$ Mean & Bet & 0.0114 & 0.0030 & {$[0.0063,0.0180]$} \\
\hline$\rho_{m}$ & $\Delta \ln M$ AR1 Coef. & Beta & 0.6278 & 0.0800 & {$[0.4653,0.7767]$} \\
\hline$\sigma_{\mu}$ & $\Delta \ln M$ Shock Std. & Beta & 0.0064 & 0.0012 & {$[0.0043,0.0090]$} \\
\hline$a_{\varsigma}$ & Taylor Rule $\mathbf{E}_{t} \varsigma_{t+1}$ Coef. & Normal & 1.8250 & 0.2300 & {$[1.3742,2.2758]$} \\
\hline$a_{\hat{Y}}$ & Taylor Rule $\hat{Y}_{t}$ Coef. & Normal & 0.1000 & 0.0243 & {$[0.0524,0.1476]$} \\
\hline$\rho_{R}$ & Taylor Rule AR1 Coef. & Beta & 0.6490 & 0.0579 & {$[0.5317,0.7578]$} \\
\hline$\sigma_{u}$ & Taylor Rule Shock Std. & Beta & 0.0051 & 0.0016 & {$[0.0025,0.0087]$} \\
\hline
\end{tabular}

The calibration relies on existing DSGE model literature; see the text for details. For a non-informative prior, the right most column contains the lower and upper end points of the uniform distribution. When the prior is based on the beta distribution, its two parameters are $a=\bar{\Gamma}_{i, n}\left[\left(1-\bar{\Gamma}_{i, n}\right) \bar{\Gamma}_{i, n} / S T D\left(\Gamma_{i, n}\right)^{2}-1\right]$ and $b=a\left(1-\bar{\Gamma}_{i, n}\right) / \bar{\Gamma}_{i, n}$, where $\bar{\Gamma}_{i, n}$ is the degenerate prior of the $i$ th element of the parameter vector of model $n=1, \ldots, 4$, and its standard deviation is $\operatorname{STD}\left(\Gamma_{i, n}\right)$. 


\section{TABLE 2: CIC OF KOLMOGOROV-SMIRNOV STATISTICS}

\begin{tabular}{|c|c|c|c|c|c|c|c|c|}
\hline Model & \multicolumn{2}{|c|}{$\begin{array}{c}\Delta Y \mathrm{w} / \mathrm{r} / \mathrm{t} \\
\text { Trend Sh'k }\end{array}$} & \multicolumn{2}{|c|}{$\begin{array}{c}\Delta Y \mathrm{w} / \mathrm{r} / \mathrm{t} \\
\text { Transitory Sh'k }\end{array}$} & \multicolumn{2}{|c|}{$\begin{array}{c}\Delta C \mathrm{w} / \mathrm{r} / \mathrm{t} \\
\text { Trend Sh'k }\end{array}$} & \multicolumn{2}{|c|}{$\begin{array}{c}\Delta C \mathrm{w} / \mathrm{r} / \mathrm{t} \\
\text { Transitory Sh'k }\end{array}$} \\
\hline \multicolumn{9}{|c|}{ Non-Habit NKDSGE } \\
\hline \multicolumn{9}{|l|}{ Baseline } \\
\hline MGR & 0.02 & 0.03 & 0.00 & 0.01 & 0.00 & 0.00 & 0.00 & 0.00 \\
\hline $\mathrm{TR}$ & 0.01 & 0.00 & 0.12 & 0.71 & 0.00 & 0.00 & 0.08 & 0.68 \\
\hline \multicolumn{9}{|l|}{ SPrice } \\
\hline MGR & 0.03 & 0.47 & 0.00 & 0.23 & 0.01 & 0.17 & 0.00 & 0.04 \\
\hline $\mathrm{TR}$ & 0.40 & 0.57 & 0.00 & 0.76 & 0.01 & 0.16 & 0.00 & 0.49 \\
\hline \multicolumn{9}{|l|}{ SWage } \\
\hline MGR & 0.00 & 0.00 & 0.00 & 0.06 & 0.00 & 0.00 & 0.00 & 0.06 \\
\hline TR & 0.00 & 0.00 & 0.21 & 0.37 & 0.00 & 0.00 & 0.02 & 0.81 \\
\hline \multicolumn{9}{|c|}{ Habit NKDSGE } \\
\hline \multicolumn{9}{|l|}{ Baseline } \\
\hline MGR & 0.00 & 0.04 & 0.16 & 0.18 & 0.02 & 0.16 & 0.13 & 0.18 \\
\hline $\mathrm{TR}$ & 0.00 & 0.03 & 0.64 & 0.52 & 0.03 & 0.14 & 0.53 & 0.85 \\
\hline \multicolumn{9}{|l|}{ SPrice } \\
\hline MGR & 0.14 & 0.64 & 0.11 & 0.59 & 0.09 & 0.44 & 0.29 & 0.49 \\
\hline $\mathrm{TR}$ & 0.43 & 0.74 & 0.29 & 0.65 & 0.15 & 0.46 & 0.33 & 0.76 \\
\hline \multicolumn{9}{|l|}{ SWage } \\
\hline MGR & 0.00 & 0.01 & 0.18 & 0.23 & 0.01 & 0.10 & 0.13 & 0.23 \\
\hline TR & 0.00 & 0.05 & 0.55 & 0.45 & 0.03 & 0.13 & 0.44 & 0.77 \\
\hline
\end{tabular}

Baseline NKDSGE models include sticky prices and sticky wages. The acronyms SPrice and SWage represent NKDSGE models with only sticky prices or sticky nominal wages, respectively. The money growth and Taylor rules of equations (8) and (9) are denoted by MGR and the TR, respectively. The column headings $[0, \pi]$ and $[8,2]$ indicate that the $C I C$ quantifies the intersection of $K S_{\mathcal{P}}$ and $K S_{\mathcal{T}}$ statistic distributions computed from permanent and transitory $S D$ s of $\Delta Y$ and $\Delta C$ with domains on the entire spectrum (i.e., from frequency zero or the long run to the short run), and from 8 to 2 years per cycle, respectively. 
Figure 1: $\triangle C$ AND A REAL INTEREST RATE SHOCK: IMPULSE RESPONSE FunCTIONS AND SDS
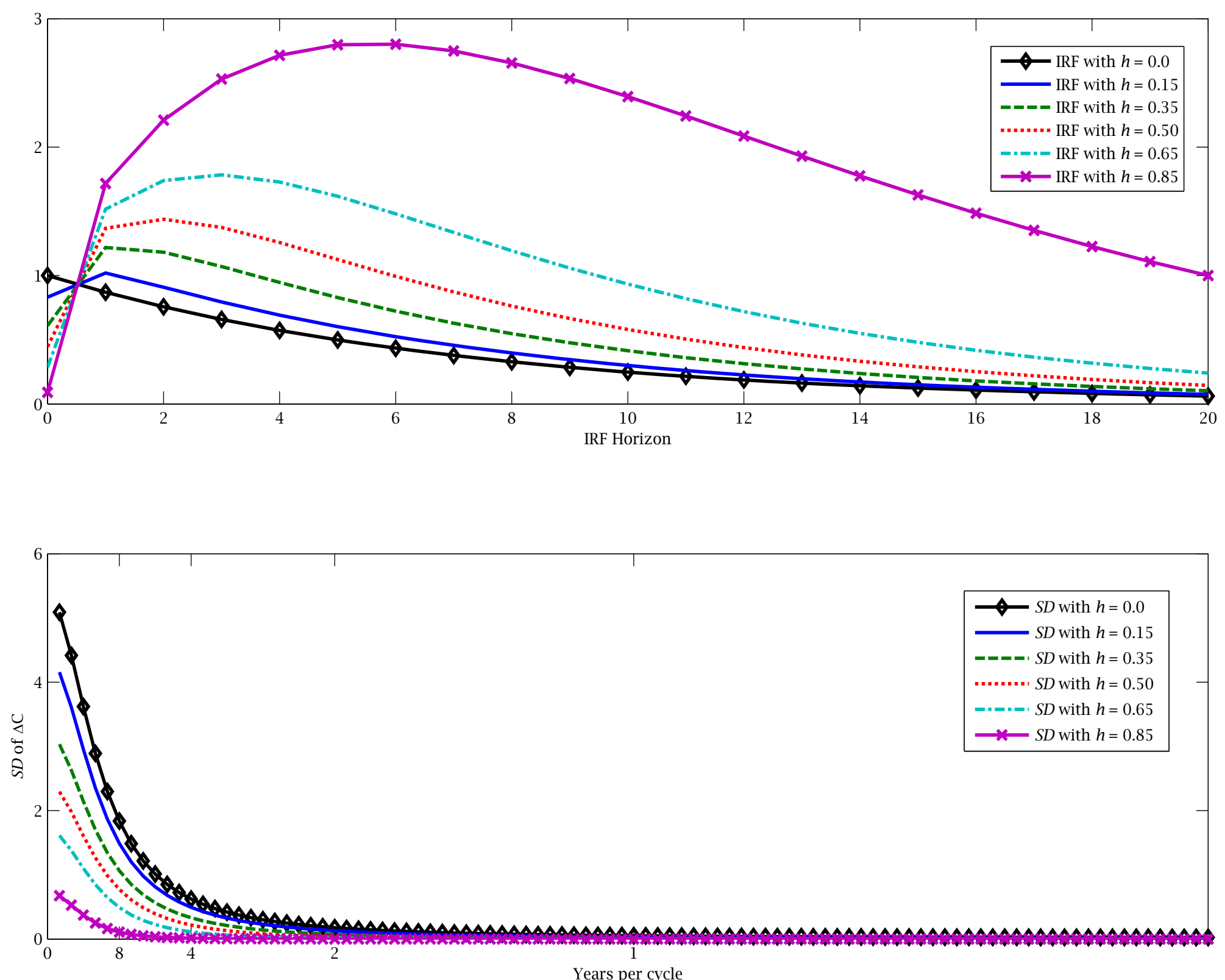

The top (bottom) window plots the impulse response functions ( $S D s$ ) of $\Delta C$ generated from the solved linearized Euler (2) given a 1 percent shock to the forecast innovation of the $\mathrm{AR}(1)$ of the real rate, $q_{t}$. 
Figure 2: MEAN PERMANENT AND TRANSITORY $S D_{\mathcal{P}}$ S
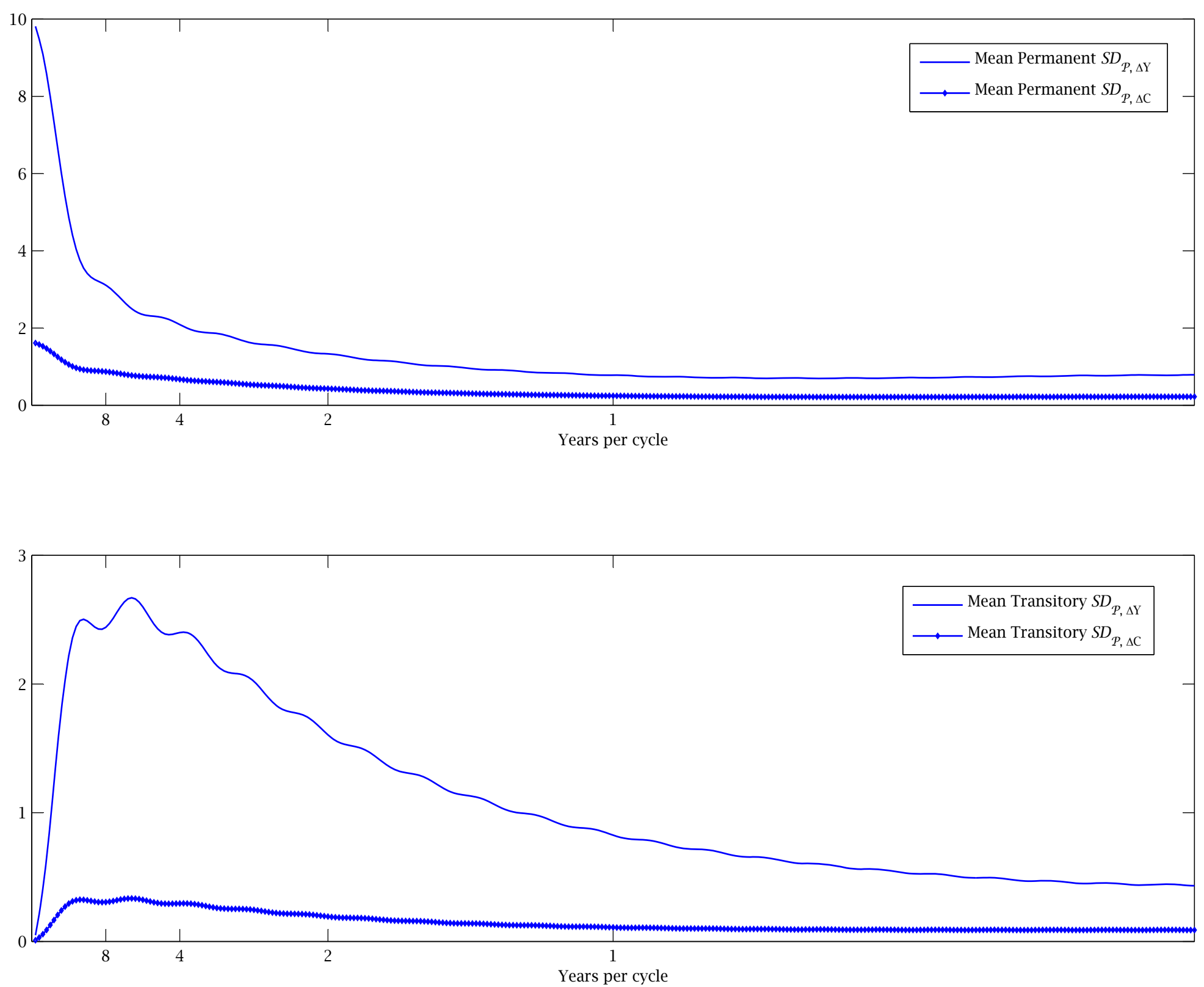

Mean permanent and transitory $S D_{\mathcal{P}, \Delta Y}$ and $S D_{\mathcal{P}, \Delta C}$ are averaged frequency by frequency across ensembles that consist of $\mathcal{J}$ of these $S D$ s. The $S D$ s are constructed using SVMA $(\infty)$ s that rely on LRMN, the BQ decomposition, unrestricted VAR(2)s. 


\section{Figure 3: $\quad$ MeAN STRUCTURAL $S D_{\mathcal{P}} S$ AND $S D_{\mathcal{T}} S$ OF BASEline NKDSGE MODELS}
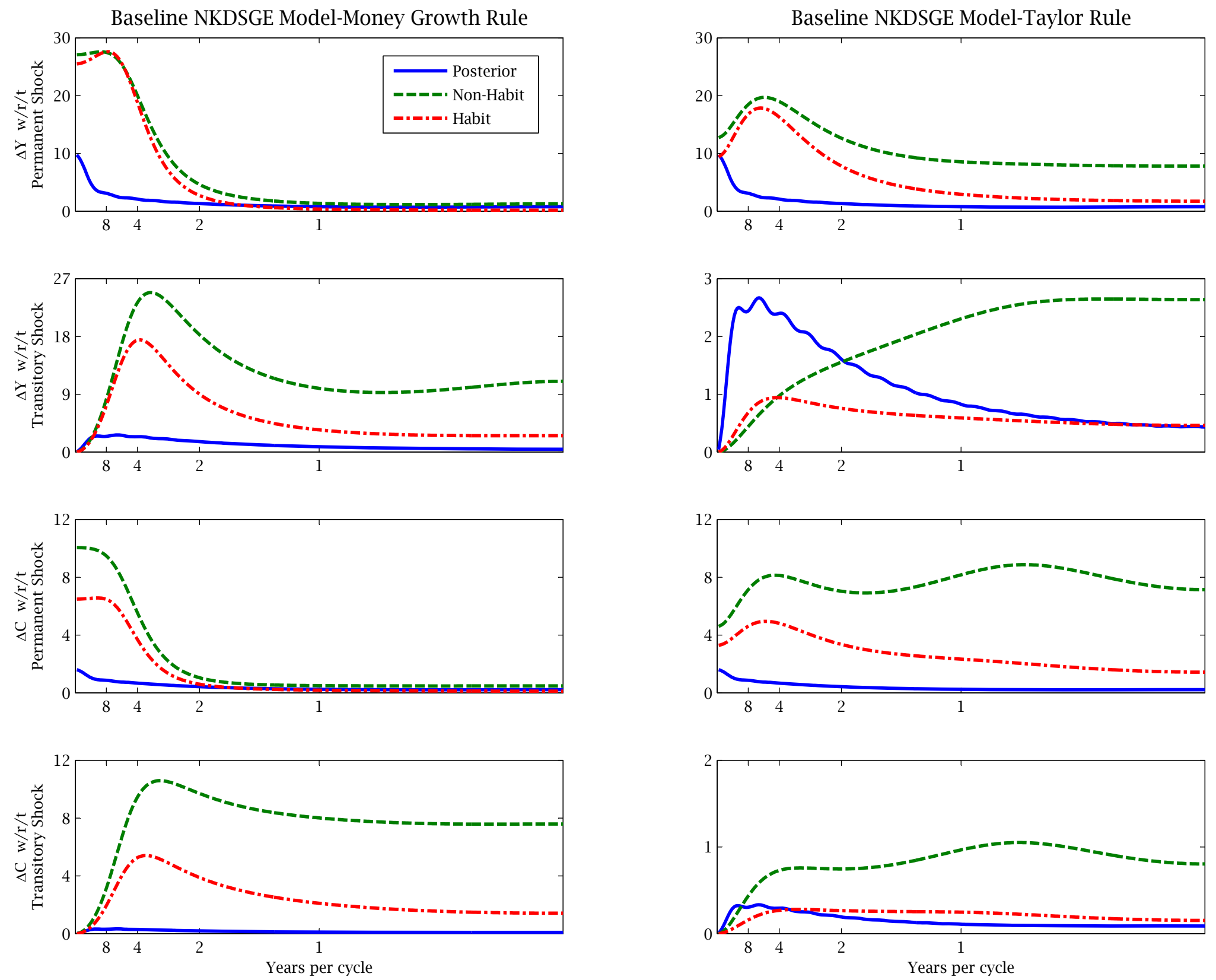

The habit and non-habit NKDSGE models generate ensembles of permanent and transitory $S D_{\mathcal{T}, \Delta Y} \mathrm{~s}$ and $S D_{\mathcal{T}, \Delta C} \mathrm{~S}$ that are averaged frequency by frequency to produce the mean $S D_{\mathcal{T}}$ s. Otherwise, see the notes to figure 2. 
Figure 4: MeAN STRuctural $S D_{\mathcal{P}} S$ AND $S D_{\mathcal{T}}$ S OF SPRICE NKDSGE Models
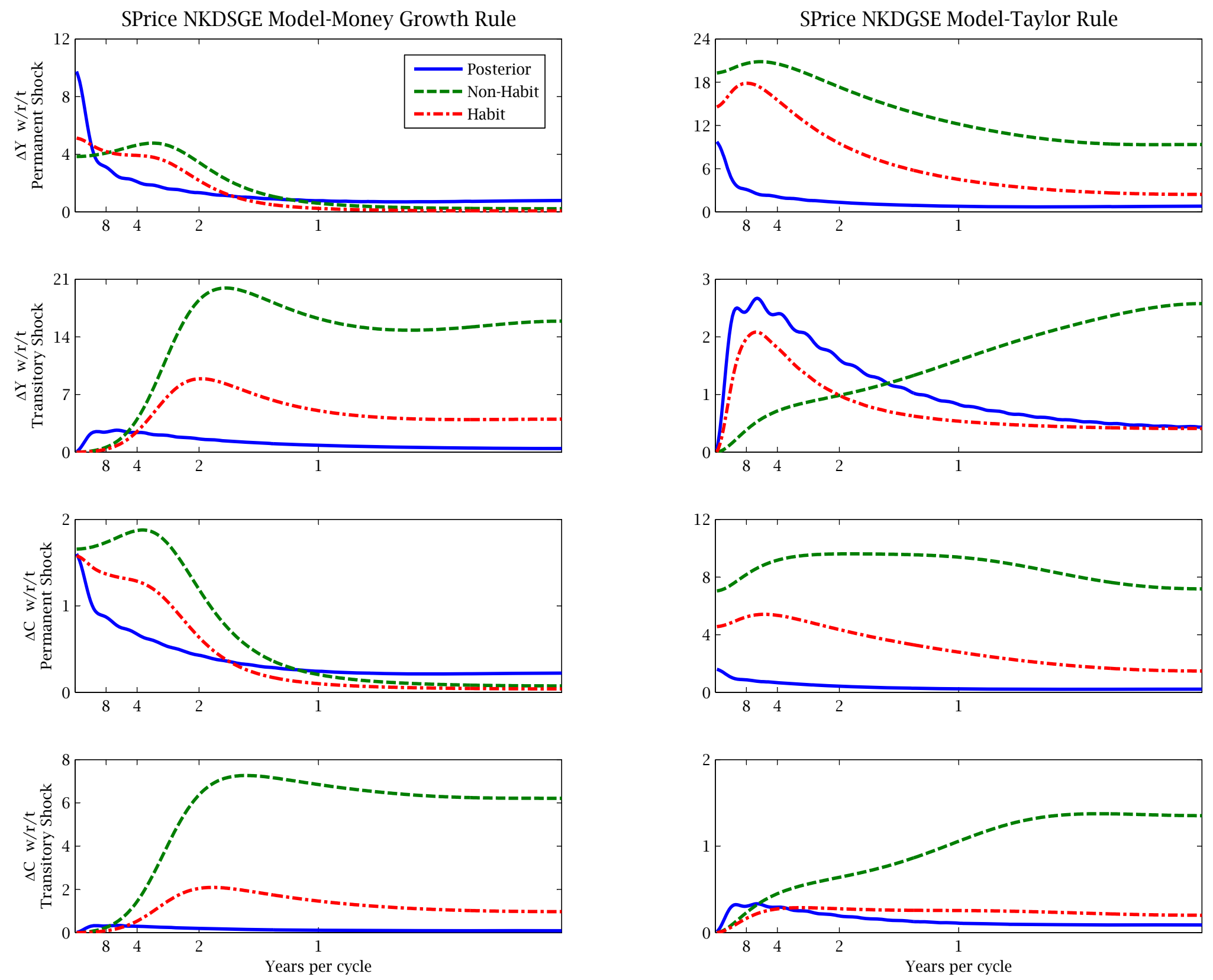

See figure 3 for details. 
Figure 5: MeAn STRUCTURAL $S D_{\mathcal{P}} S$ AND $S D_{\mathcal{T}}$ S OF SWAGE NKDSGE ModelS
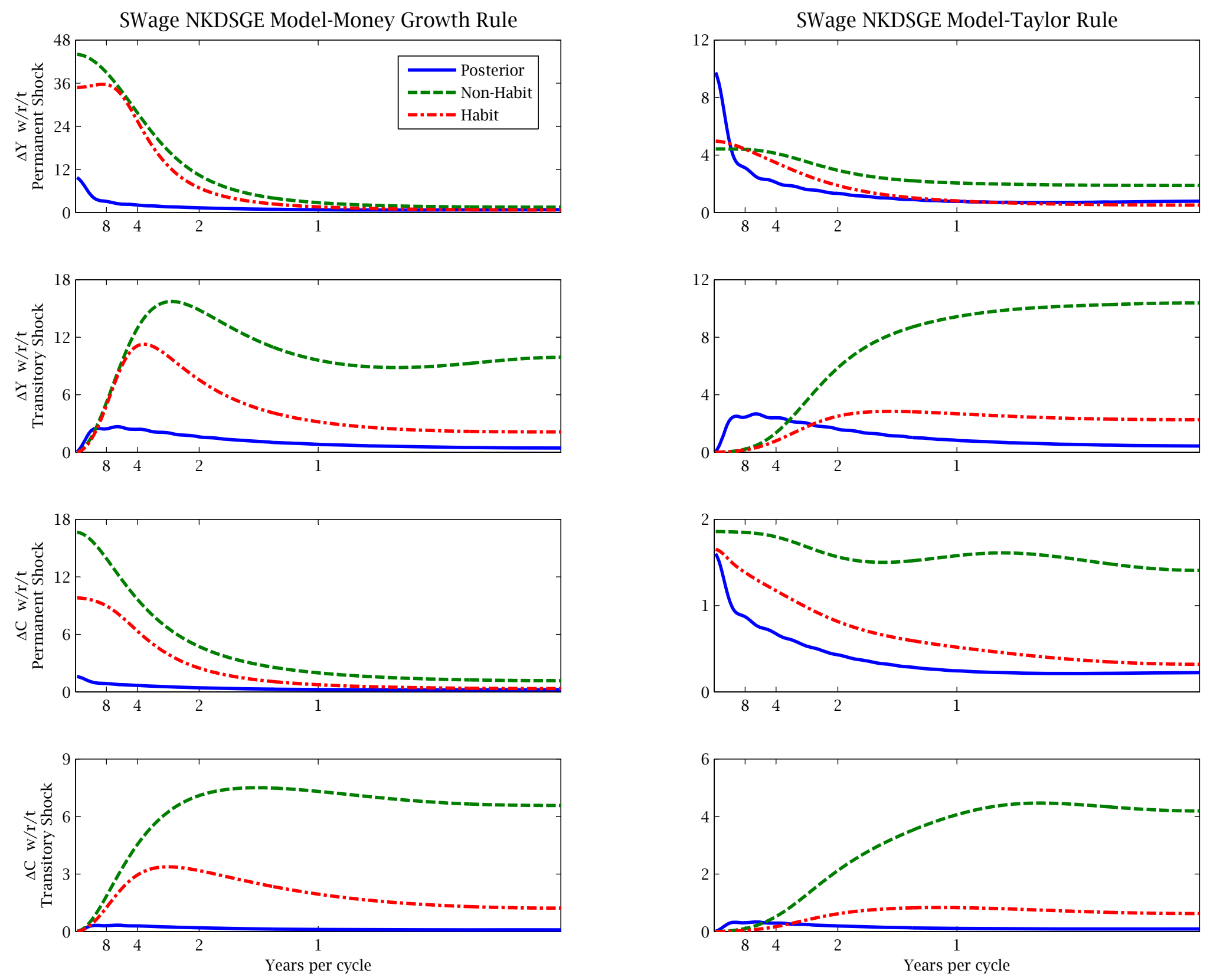

See the notes to figure 3 . 